\title{
$N-03$
}

NASA Technical Memorandum 105976

AIAA-93-0174

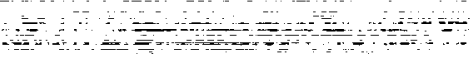

$13652 \%$

P.23

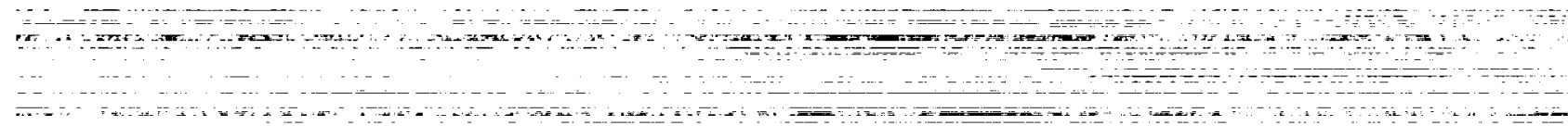

\section{Ice Accretion Prediction for a Typical Commercial Transport Aircraft}

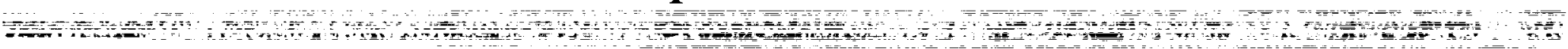

C.S. Bidwell

Lewis Research Center

Cleveland, Ohio

Prepared for the

31st Aerospace Sciences Meeting and Exhibit

sponsored by the American Institute of Aeronautics and Astronautics

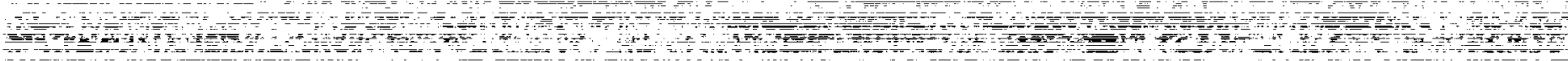

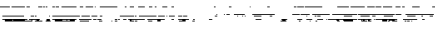

Reno, Nevada, January 11-14, 1993

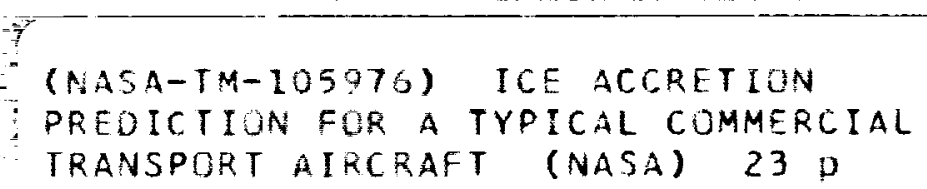

NASก

$N 93-15522$

Unclas

$63 / 03 \quad 0136521$ 


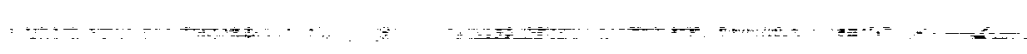

. 


\title{
Ice Accretion Prediction For a Typical Commercial Transport Aircraft
}

\author{
C. S. Bidwell \\ National Aeronautics and Space Administration \\ Lewis Research Center \\ Cleveland, Ohio
}

\section{SUMMARY}

Ice accretion calculations were made for a modern commercial transport using the NASA, Lewis LEWICE3D ice accretion code. The ice accretion calculations were made for the wing and horizontal tail using both isolated flow models and flow models incorporating the entire airplane. The isolated flow model calculations were made to assess the validity of using these simplified models in lieu of the entire model in the ice accretion analysis of full aircraft. Ice shapes typifying a rime and a mixed ice shape were generated for a 30 minute hold condition. In general, the calculated ice shapes looked reasonable and appeared representative of a rime and a mixed ice conditions. The isolated flow model simplification was good for the main wing except at the root where it overpredicted the amount of accreted ice relative to the full aircraft flow model. For the horizontal tail the size and amount of predicted ice compared well for the two flow models, but the position of the accretions were more towards the upper surface for the aircraft flow model relative to the isolated flow model. This was attributed to downwash from the main wing which resulted in a lower effective angle-of-attack for the aircraft horizontal tail relative to the isolated horizontal tail.

\section{NOMENCLATURE}

\begin{tabular}{|c|c|}
\hline AAOA & Airplane angle-of-attack, degrees \\
\hline b & Span of wing, $m$ \\
\hline $\mathrm{C}$ & Chord length, $m$ \\
\hline $\mathrm{C}_{\mathrm{p}}$ & Pressure coefficient \\
\hline$d^{P}$ & Droplet diameter, $\mu \mathrm{m}$ \\
\hline $\mathbf{K}_{\mathbf{s}}$ & Roughness factor, $\mathrm{m}$ \\
\hline LWC & Liquid Water Content, $\mathrm{g} / \mathrm{m}^{3}$ \\
\hline MVD & Median Volume Diameter, $\mu \mathrm{m}$ \\
\hline $\begin{array}{l}\text { United St } \\
\text { ment has } \\
\text { the copyr } \\
\text { All oth }\end{array}$ & $\begin{array}{l}\text { ie American Insitute of Aeronautics } \\
\text { c. No copyright is asserred in the } \\
\text { le } 17 \text {. U.S. Code. The U.S. Govern- } \\
\text { license to exercise all rights under } \\
\text { herein for Governmental purposes. } \\
\text { eserved by the copyright owner. }\end{array}$ \\
\hline
\end{tabular}




$\begin{array}{ll}\mathrm{P} & \text { Free stream pressure, } \mathrm{Pa} \\ \mathrm{s} & \text { Surface distance, } \mathrm{cm} \\ \mathrm{t} & \text { Ice accretion time, seconds } \\ \mathrm{T} & \text { Free stream temperature, } \mathrm{K} \\ \mathrm{V} & \text { Free stream velocity, } \mathrm{m} / \mathrm{s} \\ \mathrm{y} & \text { Spanwise distance from root, } \mathrm{m} \\ \beta & \text { Collection efficiency }\end{array}$

\section{INTRODUCTION}

The problem of aircraft icing has plagued man since the beginning of flight. Ice, in general causes increased drag, decreased lift, decreased propulsive thrust, increased weight, reduced stability, etc., all of which can make an aircraft less controllable and more prone to fall out of the sky. Simultaneously with the problem of icing came the desire to rid ourselves of this problem, which led to the task of trying to understanding the ice accretion phenomena. To better protect aircraft from the icing, the icing phenomena needed to be understood. Early attempts at understanding the cause and effects of icing included various flight tests and some open air icing tests atop Mount Washington (Ref. 1). Some early analytical work was done by Langmuir and Blodgett to calculate the collection efficiencies of cylinders using a mechanical integrator with numerous simplifications (Ref. 2). Much was done to quantify the effect of icing, but limited insight was gained into the underlying physics of icing due to deficiencies in the analytical and experimental tools available to the early researchers. From this early work, conservative engineering tools were developed which allowed design of ice protection systems and allowed aircraft to fly safely.

With the advent of high speed computers in the past sevaral decades and the desire to optimize system design, the task of analytically predicting the icing phenomena has been undertaken. Many computer codes have been written in the past decade which calculate ice accretions for $2 \mathrm{D}$ airfoils (Ref. 3-6). Calculations of ice accretion for some simple 3D geometries have been made in the past several years (Ref. 7-9). These cases have been limited to isolated portions of an aircraft and mainly to the wing and tail sections. The work presented here is the first work which attempts to analyze the entire aircraft and the first work which attempts to assess the validity of the isolated model simplification. Ice accretion predictions on the wing and horizontal tail were

made using the aerodynamic model of the entire aircraft and using isolated aerodynamic models. A typical commercial transport configuration was used for the calculations.

\section{ANALYTICAL METHOD}

The NASA, Lewis ice accretion code (LEWICE3D) was used to do the ice accretion analysis (Ref. 10). This computer program has been used in previous calculations of isolated, finite wings (Ref. 7-9). This work represents the first application of the code to the full aircraft.

The LEWICE3D code incorporates flow, trajectory, heat transfer and geometry modification analysis into a single computer program with a multitude of capabilities. Flow can be calculated for arbitrary 3D lifting and nonlifting bodies with external flow. Calculations of arbitrary 
streamlines and trajectories are possible. The code has the capability to calculate tangent trajectories and impingement efficiencies for single droplets or droplet distributions. Ice accretions can be calculated at arbitrary regions of interest for lifting surfaces in a multistep fashion in either a surface normal or tangent trajectory direction. Additionally, geometry for lifting surfaces (i.e. airfoil surfaces) can be modified automatically at each time step to reflect the ice shape.

The methodology used in the LEWICE3D analysis can be broken into seven basic steps for each section of interest at each time step. In the first step the flow field is generated. Secondly, surface streamlines are calculated. Thirdly, tangent trajectories are calculated at the region of interest. An array of particles is released between the tangent trajectories in the fourth step. These impacting particles are used to calculate collection efficiency as a function of surface distance. The fifth step involves interpolating or extrapolating the collection efficiencies onto the streamlines. In the sixth step the ice accretion for the streamline is calculated. During the seventh and final step the geometry is modified.

There are four basic program elements contained in the LEWICE3D jobstream; a flow analysis, a trajectory analysis, a streamline analysis and an ice accretion analysis. The flow code is basically the 1st order, 3D panel code of Hess-Smith (Ref. 11-12) for arbitrary lifting and nonlifting bodies with external flow with modifications by Hillyer Norment (Ref. 14) to allow leaking panels (used to simulate mass flows through orifices). It incorporates variable dimensioning to allow easy adoption to different sized computers and problems. The trajectory analysis is basically that of Hillyer Norment with modifications by Bidwell and Mohler (Ref. 10) to the velocity calculation (vectorized) and by Bidwell to the tangent trajectory search scheme (replaced with more efficient scheme). At the heart of the trajectory analysis is the variable step predictor-corrector integration scheme by Krogh (Ref. 15). The surface streamline analysis uses a variable step size fourth-order Runge-Kutta integration scheme developed by Bidwell (Ref. 10). The ice accretion model is basically that of the LEWICE2D code applied along surface streamlines (Ref. 4, 16).

\section{CONFIGURATION}

The conditions and geometry for the analysis were chosen to typify a commercial transport in a hold condition. The configuration used in the analysis, which was similar to a Boeing 737 airplane, was chosen to be consistent with those of a wind tunnel model to be used at Langley Research Center for iced stability and control measurements. The coordinates for this model were obtained from Simha Dodbele at Langley Research Center. A hold condition was chosen because it was a crucial design point for the ice protection systems on a commercial transport.

The aircraft model used was a simplified version of the Boeing 737 airplane. The engine nacelles and engine pylons were not included in the flow model. The wings were modeled using a single element model with retracted flaps and slats. The deletion of these features from the aircraft should not be deemed too severe considering the position of the engines and the position of the flaps and slats in a typical hold condition.

Two flight conditions were chosen to explore limiting points of interest in the icing envelope for a hold condition. These points yield a typical rime and mixed icing condition. For both 
flight conditions the airplane angle-of-attack, yaw angle, altitude, and airspeed were chosen to be 0 degrees, 0 degrees, $1000 \mathrm{~m}$, and $135 \mathrm{~m} / \mathrm{s}$ respectively. The hold or icing time for both conditions was chosen to be 30 minutes. In addition, for both flight conditions a Median Volume Diameter (MVD) of 20 microns was chosen as indicative of a typical drop size. A temperature of $243.1 \mathrm{~K}$ and an LWC of $.20 \mathrm{~g} / \mathrm{m} 3$ were chosen for the rime case. A temperature of $263.7 \mathrm{~K}$ and an LWC of $.695 \mathrm{~g} / \mathrm{m} 3$ were chosen for the mixed case.

The computer program parameters were chosen from experience, correlations and a desire to limit the computational resources required. A single drop size and icing time step were chosen for the calculations The calculations were made at 6 spanwise stations on the wing and at 3 spanwise stations on the horizontal tail. In the wing analysis 3 spanwise stations were distributed on the outer portion of the wing and 3 were distributed on the shoulder or inner portion of the wing. The spanwise stations were chosen to be at the $10 \%, 50 \%$ and $90 \%$ stations on the outer wing, the inner wing, and the horizontal tail. The $10 \%$ and $90 \%$ span stations were chosen as conservative spanwise limits for the LEWICE3D methodology. Outside of these limits spanwise pressure gradients become large and the strip theory assumptions built into the LEWICE3D ice accretion code can be violated. The full aircraft calculations for the wing and horizontal tail were done separately using different aerodynamic models. The aerodynamic models used for each of the cases was refined in the area where the ice accretions were to be calculated. This allowed for fewer panels and smaller computational times.

Additional calculations were made using isolated models of the wing and tail. These were done to understand the correlation between the full airplane result and the isolated airfoil result, The isolated airfoil simplification is commonly used in the icing analysis of aircraft to reduce cost and complexity. A typical isolated model may have $60 \%$ fewer panels than its full aircraft counterpart, resulting in a $60 \%$ savings in computer time. The calculations were made on the NASA Lewis Research Center CRAY XMP and on an IRIS Model 4D/440/VGX. The calculations for the entire aircraft, which included 6 stations on the wing and 3 stations on the horizontal tail, required approximately 10 hours of CPU time on the Cray XMP and approximately 100 hours of CPU time on the IRIS workstation. The isolated calculations, which were made at the same locations, required approximately 4 hours and 40 hours of CPU time on the CRAY XMP and IRIS workstation respectively.

\section{ANALYSIS}

Two icing conditions and two aerodynamic flow models were used in the analysis of the wing and horizontal tail. The two icing conditions were chosen to explore a rime and a mixed ice hold condition for the wing and tail. Two flow models were used in the analysis of the wing and tail elements; an isolated model of the element ("isolated" model), and a model with the element and the remainder of the aircraft modeled (the "aircraft" model). The isolated flow models were used to assess the validity of using the isolated flow model instead of the actual flow model in the icing analysis.

The wing analysis panel models are shown in Figures 1 and 2 . The isolated model contained 4320 panels while that of the aircraft model contained 7292 panels. Figure 3 depicts the airfoil section at the five spanwise stations where the analysis was done. In general the wing was 
complex, having taper, twist and airfoil section variation. Figure 4 shows the pressure distributions at each of the spanwise stations for the models. For both models the section lift coefficient increases as the root is approached due to the twist in the wing. The agreement in the pressure distribution at the tip is almost perfect for the two models, but falls off as the root is approached. The section lift coefficient for the isolated model is greater than for the aircraft model due to the effect of the fuselage.

The collection efficiency for the two aerodynamic wing models is shown if Figure 5 . In general, for both models, the shape of the collection efficiency curves were similar except for the most inboard section. The curves show that the majority of water is collecting on the upper surface (i.e. a negative surface distance from the highlight) indicative of a negative angle-of-attack, although the wing was at a slight positive angle-of-attack. This was due to the low angle-of-attack and camber of the wing. The shapes of the collection efficiency curves are similar at the outer four stations because the airfoil sections are similar. The airfoil sections at the two inboard sections are much blunter hence the collection efficiency curves are more rounded. In general, for the three outer stations, the maximum collection efficiency decreased while the upper and lower impingement limits moved more towards the underside or pressure side of the wing as the root was approached. This is due to the increased inertia parameter (resulting from the increased chord) and effective angle-of-attack as the root is approached. At the fourth station, which has the same section as the outer three stations, the maximum collection efficiency decreased relative to the outer three station but the extent of impingement increased slightly. This can be attributed to the increase in the sweep angle of the leading edge at the inboard portion of the wing. Increased sweep angle causes a reduction in maximum collection efficiency and an increase in extent of impingement. At the fifth and sixth stations the maximum collection decreased and the extent of impingement increased over the outer stations. This decrease in maximum collection efficiency can be attributed to the increase in chord, while the increased extent of impingement can be attributed to the increased sweep angle and the blunter section shape.

As was the case for the pressure distribution, the agreement in collection efficiency between the two models is almost perfect at the tip, but worsens as the root is approached (Figure 6). Only at the inner two stations is there in appreciable difference in the collection efficiency curves. At the fifth station for both models, the maximum collection efficiency and the lower impingement limits are about the same, while the upper impingement limit of the airplane wing is increased slightly over the lower impingement limit of the isolated wing. This is due to a difference in effective angle-of-attack between the two models. The airplane wing at this station has a slightly smaller effective angle-of-attack than the isolated wing hence the droplets impinge further back on the upper surface. At the sixth and most inboard station the maximum collection efficiency and upper impingement for both models is about the same while the lower impingement limit is further back for the isolated model. This can be explained once again by the fact that the aircraft wing is at a lower effective angle-of-attack than the isolated wing. The difference in the way that the lower angle-of-attack is revealed in the collection efficiency curves between the fifth and sixth section, (i. e. one shows a much different upper impingement limit and one shows a much different lower impingement limit) is due to the radically different section shapes. The most inboard section is much more rounded on its underside hence a small decrease in angle-of-attack at a relatively low angle-of-attack will produce a larger change in the lower impingement limit. At the fifth station the section is less rounded on its underside, hence a small decrease in effective 
angle-of-attack at a relatively low angle-of-attack will show up more upon the upper impingement limit.

The ice accretion shapes for both the rime and mixed conditions and for both flow models are shown in Figures 7-10. For both the rime and the mixed conditions a roughness factor of .0013 $\mathrm{m}$ was used in the ice accretion calculations. This value had been used in previous calculations with good agrement (Ref. 8). Doubling or halving the roughness factor did not significantly affect the resulting ice shape, and in light of the absence of experimental data, and the reasonable appearance of the resulting ice shapes it was deemed a good value. In general, the rime and mixed shapes looked reasonable considering the collection efficiencies and the pressure distributions observed. The ice shapes followed the trends observed for the collection efficiency. That is, as the root was approached, the ice shape height decreased and its extent increased or decreased according to the local extent of impingement. The comparison between the isolated and aircraft wing ice shapes was excellent at all but the root section. This agreement was expected considering the good agreement between collection efficiency and pressure distribution for the isolated and aircraft wing models. At the root the differences in the pressure distribution and collection efficiency produce some differences in the resulting ice shape between the isolated and aircraft wing, although not much.

The flow models for the isolated and aircraft horizontal tail are shown in Figures 11 and 12. The isolated panel model contained 1800 panels while that of the aircraft model contained 5532 panels. The airfoil sections for the three spanwise sections analyzed are shown in Figure 13. The horizontal tail was of a simple tapered design. The pressure distributions for both models are shown in Figure 14. The pressure distributions reveal a negative lift coefficient. This is due to the relatively low aircraft angle-of-attack, the inverse camber of the tail section (i.e. the tail camber was in the opposite direction of the wing camber), and the fact that the horizontal tail is mounted at a slightly negative angle-of-attack relative to the aircraft angle-of-attack (about 1 degree). Also, the pressure coefficients display a slight fall off in section lift as the root is approached, a result indicative of a simple tapered wing with no twist. From the pressure distributions it can be seen that the effective angle-of-attack for the isolated model is less than that for the actual model. The difference in effective angle-of-attack increases as the root is approached. This difference is caused by downwash from the main wing onto the horizontal tail.

The collection efficiencies for the two tail models are shown in Figure 15. In general, the maximum collection efficiency decreased, the extent of impingement increased, and the region of impingement moved more towards the upper surface of the wing as the root was approached. The decrease in the maximum collection efficiency and increase in the extent of impingement is due to the increase in chord length as the root is approached. The collection efficiency for the horizontal tail, which is relatively blunt and at a low angle-of-attack, behaves much like a swept, tapered cylinder with increasing diameter towards the root. The maximum collection efficiency for a tapered swept cylinder decreases and the extent of impingement increases as the root is approached. The migration of the impingement region towards the upper surface as the root was approached is due to the spanwise decrease in section lift or effective angle-of-attack.

As was the case for the wing, the collection efficiency differences between the isolated and aircraft flow model for the horizontal tail were small at the tip but increased as the root was 
approached (Fig. 16). As the root is approached the difference in maximum collection efficiency between the two models increased, with the actual model producing lower values. Also as the root was approached the region of impingement for the aircraft model moved increasingly towards the upper surface of the airfoil relative to the isolated model. These differences can once again be attributed to the differences in effective angle-of-attack. The aircraft model saw a smaller effective angle-of-attack than the isolated model and this difference in effective angle-of-attack increased as the root was approached. Hence the region of impingement of the aircraft model relative to the isolated model was more towards the upper surface and it moved increasingly towards the upper surface as the root was approached

The ice accretion shapes for both the rime and mixed conditions for both horizontal tail flow models are shown in Figures 17-20. As for the wing ice accretions, a roughness factor of $.0013 \mathrm{~m}$ was used to produce the ice shapes. The ice accretions, appeared reasonable and representative of rime and mixed conditions and followed the trends shown by the collection efficiencies. That is, the ice shape size decreased and extent of impingement increased as the root was approached. The agreement in size and shape between the ice accretions for the isolated and aircraft models was good. The ice accretions for the actual model were more towards the upper surface relative to the isolated flow model due to the lower effective angle-of-attack of the aircraft model relative to the isolated model.

\section{CONCLUSION}

In general, the calculated results were encouraging. The calculated flow looked reasonable considering the angles-of-attack and the potential flow assumptions used. The calculated collection efficiencies and ice shapes were consistent with previous work and intuition. Comparisons between the isolated flow model and the aircraft model were good for all but the most inboard stations for the wing and horizontal tail.

The flow solutions produced by the panel code appeared reasonable and followed traditional trends attributed to finite swept, tapered, twisted wing. The majority of the horizontal tail and wing were of the same cross section, hence variation in the pressure distribution could be attributed to effective angle-of-attack differences caused by geometric twist, taper and downwash. In all cases the size and type of variation observed could be attributed to one of these effects.

Several trends with regard to collection efficiency were observed in the study. Because the airfoil sections and sweep angle for a majority of the wing and tail were similar the trends in collection efficiency could be mainly attributed to chord length, and local angle-of-attack. The maximum collection efficiencies decreased as the root was approached for both the wing and tail models due to the increase in chord length. The limits of impingement for the swept, tapered wing could be correlated to the local effective angle-of-attack. The effective angle-of-attack of the wing increased as the root was approached due to the geometric twist, hence the limits of impingement moved more towards the pressure side of the wing. The extent of impingement on the horizontal tail, which was blunt and at a low angle-of-attack, increased as the root was approached due to the increase in chord.

In general the calculated ice shapes were reasonable and representative of the rime and 
mixed conditions from which they were derived. The ice shape height or maximum thickness decreased as the root was approached for both conditions following the maximum collection efficiency trend. Extent of ice shape also followed the extent of impingement trend.

The pressure distribution, collection efficiency and ice accretion comparisons between the isolated and actual flow models were good at all but the most inboard sections where the isolated flow model yielded more conservative results. The differences in the pressure distribution, collection efficiency, and ice accretions between the isolated and aircraft sections can be attributed to affective angle-of-attack differences between the models. In the case of the wing, the fuselage produced a slightly lower effective angle-of-attack relative to the isolated wing. For the horizontal tail the downwash from the wing caused smaller effective angle-of-attacks relative to the isolated tail. The quality of the isolated calculations were good relative to the aircraft calculations for the work presented, but caution should be used in extrapolating these results to higher angles-ofattack. At the higher angles-of-attack the differences in the effective angle-of-attack for both models will increase resulting in poorer comparisons. Methods to correct the effective angle-of-attack in the isolated cases need to be developed to make the isolated simplification more viable.

\section{REFERENCES}

1. Tribus, M.V. et al.,"'Analysis of Heat Transfer Over a Small Cylinder in Icing Conditions on Mount Washington, American Society of Mechanical Engineers Transactions", Vol. 70, 1949, pp. 871-876.

2. Langmuir, I., Blodgett, K.B. ,"A Mathematical Investigation of Water Droplet Trajectories", Army Air Forces Technical Report 5418, Feb., 1946.

3. Lozowski, E.P., and Oleskiw, M.M., "Computer Modeling of Time-Dependent Rime Icing in the A.tmosphere", CRREL 83-2, Jan. 1983

4. Ruff, G.A., Berkowitz, B.M.," Users manual for the NASA Lewis Ice Accretion Prediction code (LEWICE)", NASA CR 185129, May 1990.

5. Cebeci, T., Chen, H.H., And Alemdaroglu, N., "Fortified LEWICE with Viscous Effects." AIAA Paper 90-0754, Jan. 1990

6. Cansdale, J.T., and Gent, R.W., "Ice Accretion on Aerofoils in Two-Dimensional Compressible Flow - A Theoretical Model”, RAE TR 82128, January 1983.

7. Potapczuk, M.G. and Bidwell, C.S., "Swept Wing Ice Accretion Modeling", NASA TM 103114, Jan. 1990.

8. Potapczuk, M.G. and Bidwell, C.S., "Numerical Simulation of Ice Growth on a MS-371 Swept Wing Geometry", NASA TM 103705, Jan. 1991. 
9. Reehorst, A. L., "Prediction of Ice Accretion on a Swept NACA 0012 Airfoil and Comparisons to Flight Test Results", NASA TM 105368, Jan. 1992

10. Bidwell, C.S., and Potapczuk, M.G., "Users Manual for the NASA Lewis Three-Dimensional Ice Accretion Code (LEWICE3D)", to be published as NASA TM 105974, 1993.

11. Hess, J.L. and Smith, A.M.O., "Calculation of Non-Lifting Potential Flow About Arbitrary Bodies", Progress in Aeronautical Sciences, Volume 8, edited by D. Kuchemann, Pergammon Press, New York, 1967.

12. Hess, J.L. "Calculation of Potential Flow About Arbitrary Three-Dimensional Lifting Bodies", Report No. MDC J5679-01, Oct. 1972 Ad-755 480.

13. Mack, Dun-Pok, "Calculation of Potential Flow About Arbitrary Three-Dimensional Lifting Bodies. Users Manual”, Report No. MDS J5679-20, Oct. 1972. AD-755 933.

14. Norment, H.G., "Calculation of Water Drop Trajectories To and About Three-Dimensional Lifting and Non-lifting Bodies In Potential Airflow", NASA CR 3935, Oct. 1985.

15. Krogh, F.T. ,"Variable Order Integrators for Numerical solutions of Ordinary Differential Equations", Jet Propulsion Lab Technology Utilization Document No. CP-32308, Nov. 1970.

16. Messinger, B.L.,'Equilibrium Temperature of an Unheated Icing Surface as a Function of Airspeed", Journal of Aeronautical Sciences, Vol. 20, No. 1, 1953, pp. 29-42. 


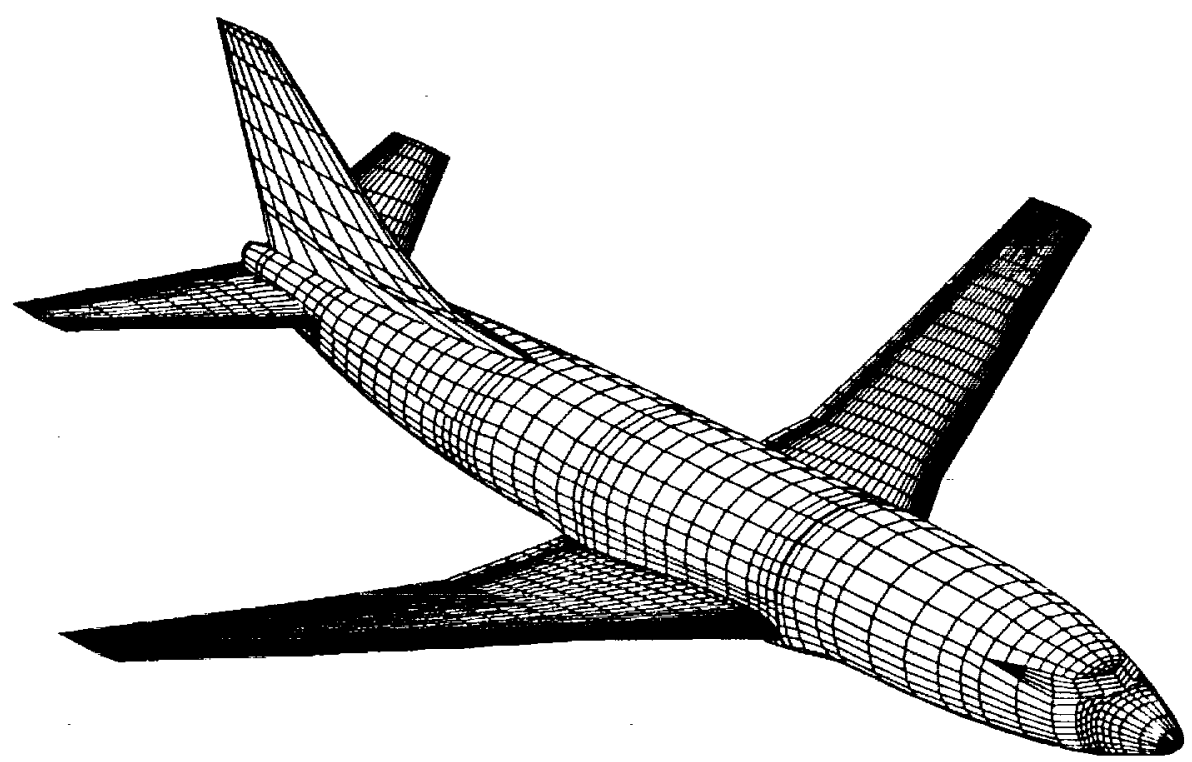

FIGURE 1. - PANEL REPRESENTATION OF AIRCRAFT MODEL USED IN AIRPLANE WING CALCULATIONS.

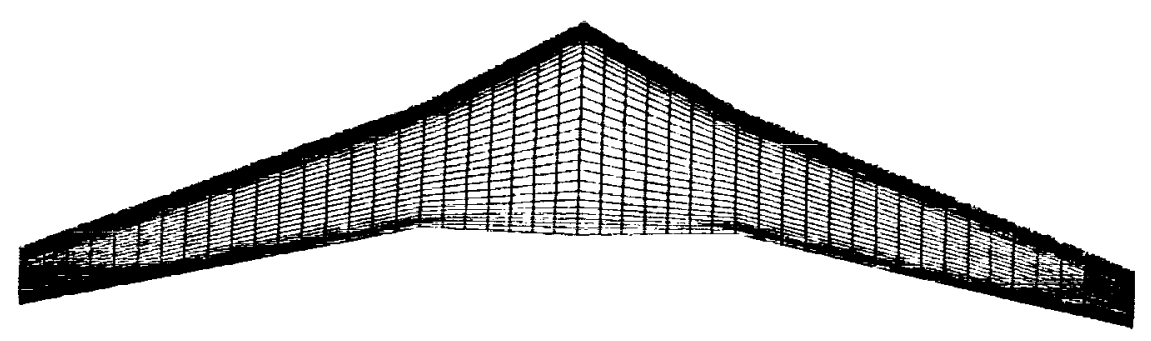

FIGURE 2. - TOP VIEW OF ISOLATED WING PANEL MODEL.

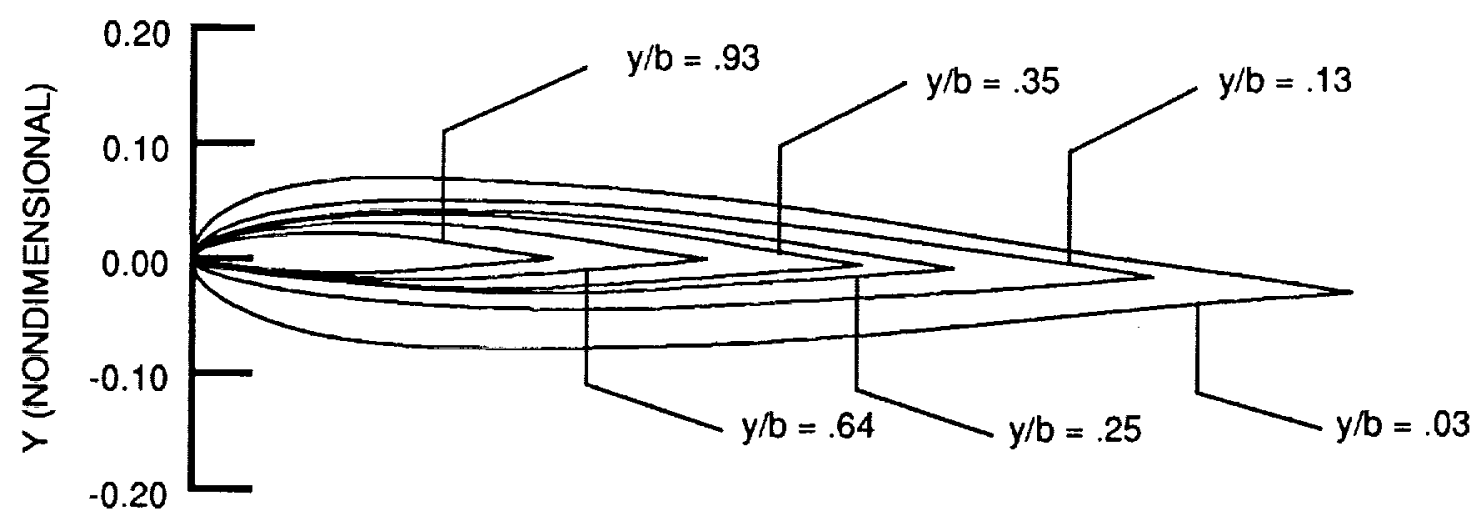

FIGURE 3. - WING PROFILE AT SEVERAL SPANWISE STATIONS. 


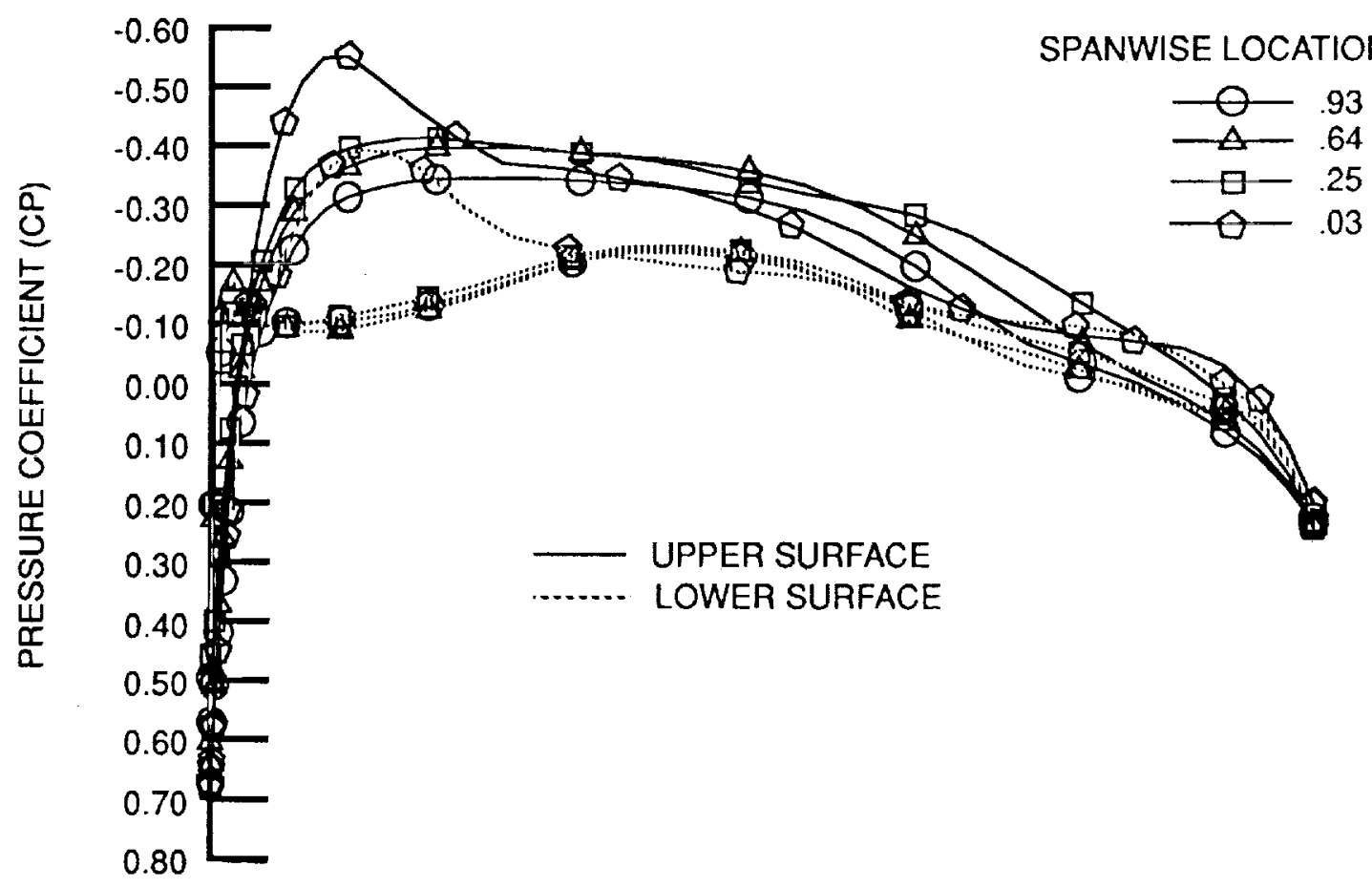

(a) AIRCRAFT WING.

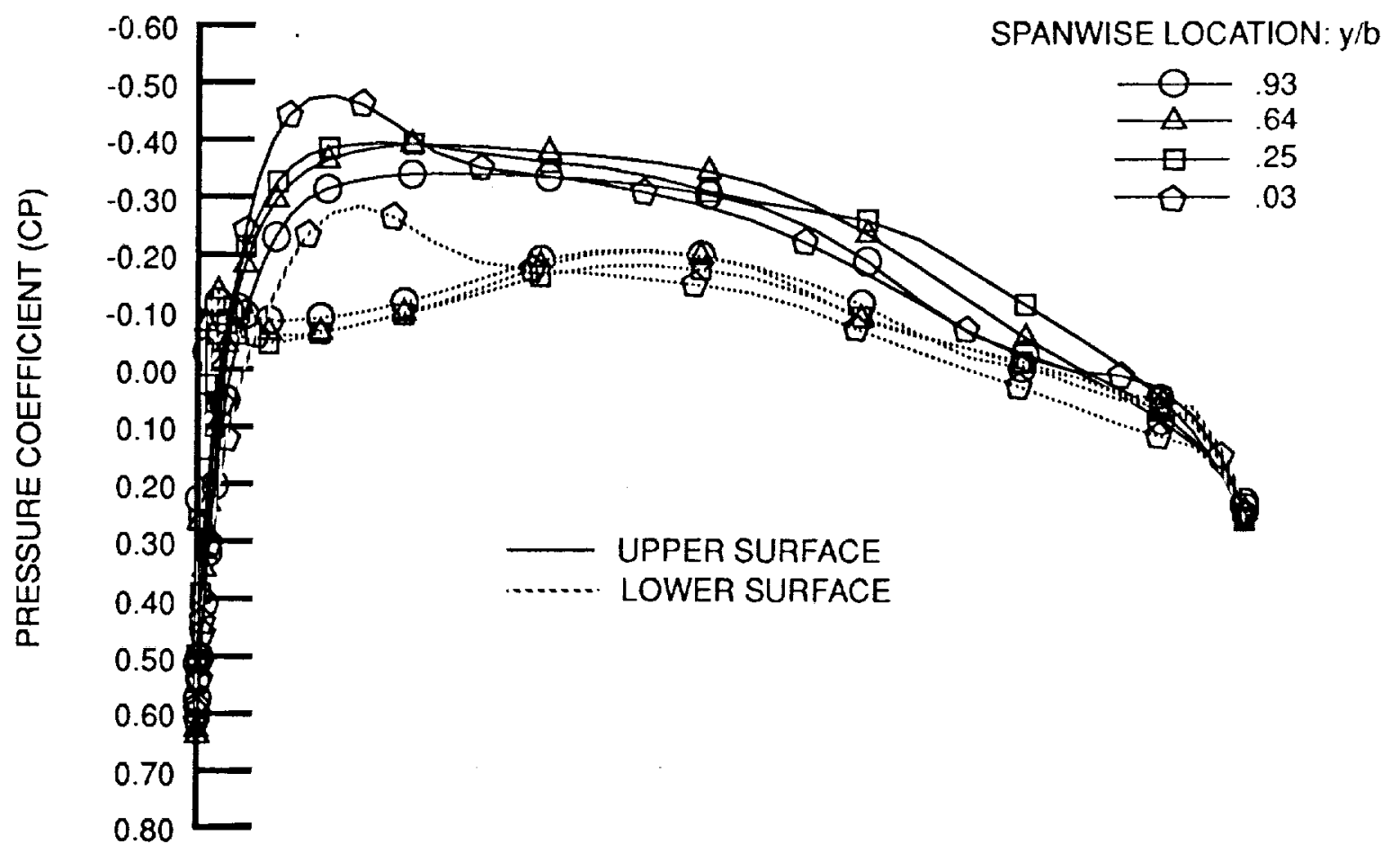

(b) ISOLATED WING.

FIGURE 4. - PRESSURE DISTRIBUTION AT SEVERAL SPANWISE LOCATIONS ON WING FOR AAOA 0 DEGREES. 


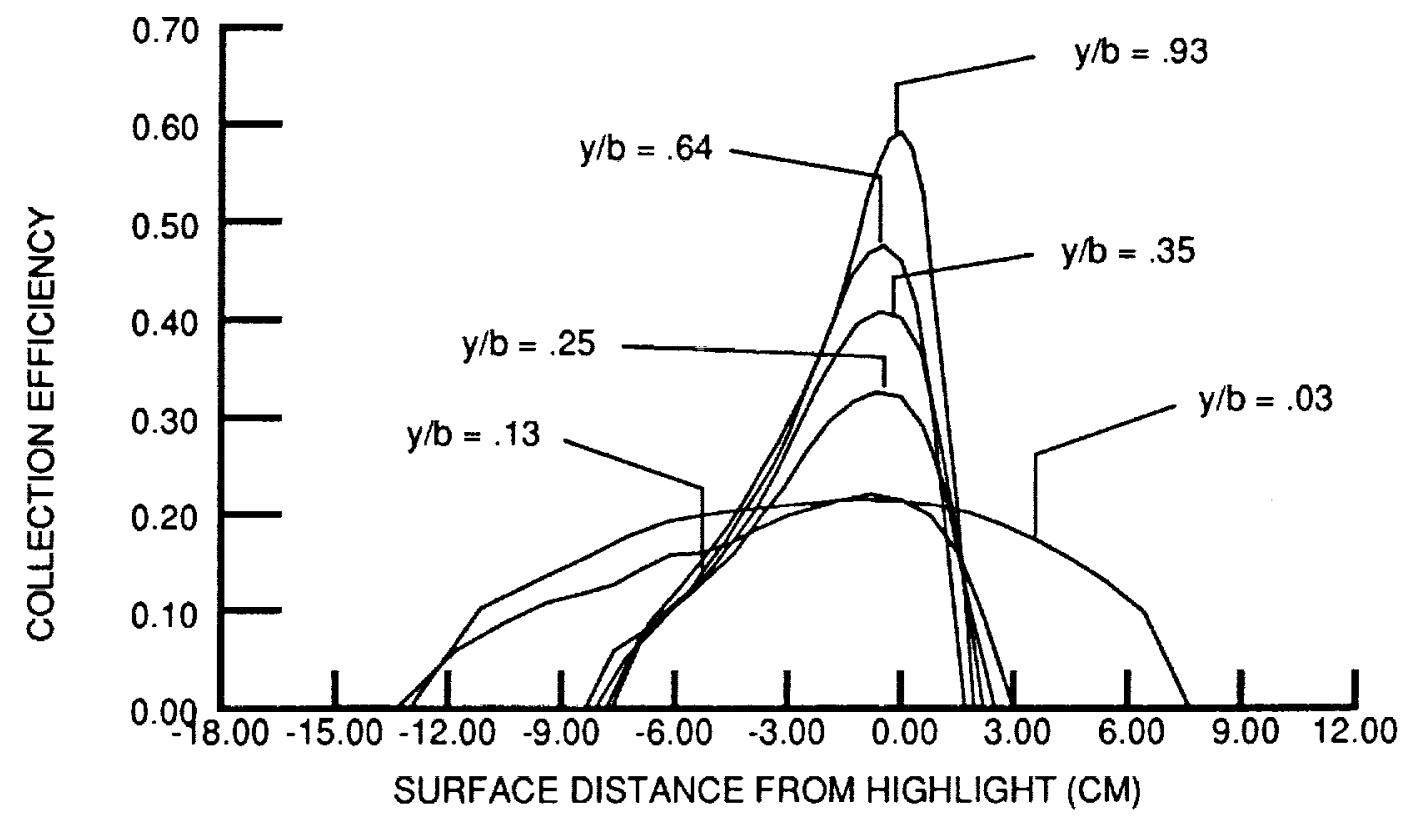

(a) AIRCRAFT WING.

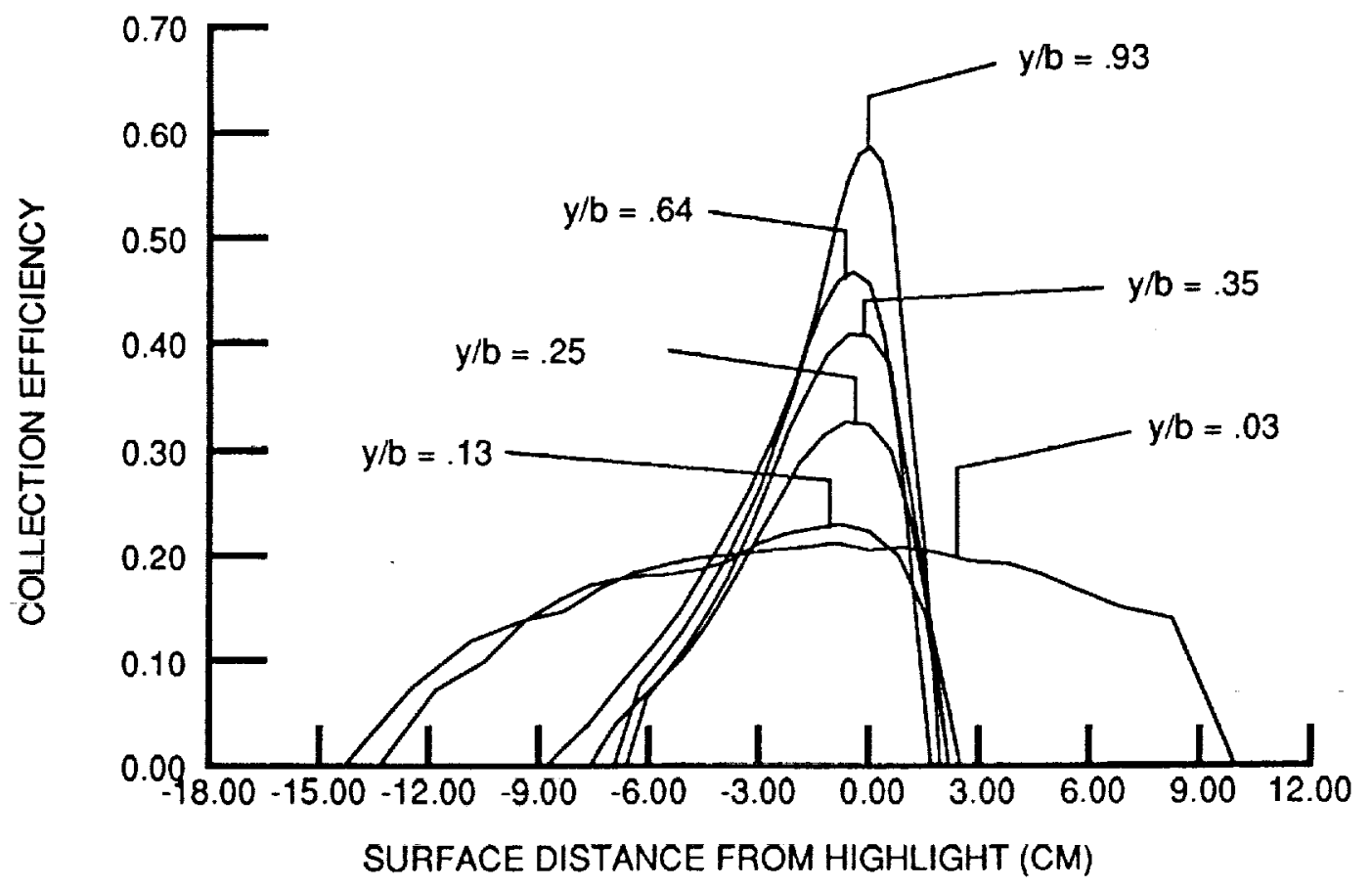

(b) ISOLATED WING.

FIGURE 5. - COLLECTION EFFICIENCY AS A FUNCTION OF SURFACE DISTANCE AT SEVERAL SPANWISE LOCATIONS ON WING. FLIGHT CONDITIONS; AIRSPEED, $135 \mathrm{M} / \mathrm{S}$, AAOA; O DEGREES, DROP SIZE; $20 \mu \mathrm{m}$, STATIC TEMPERATURE; -9.3 C, STATIC PRESSURE; $89867 \mathrm{~Pa}$. 


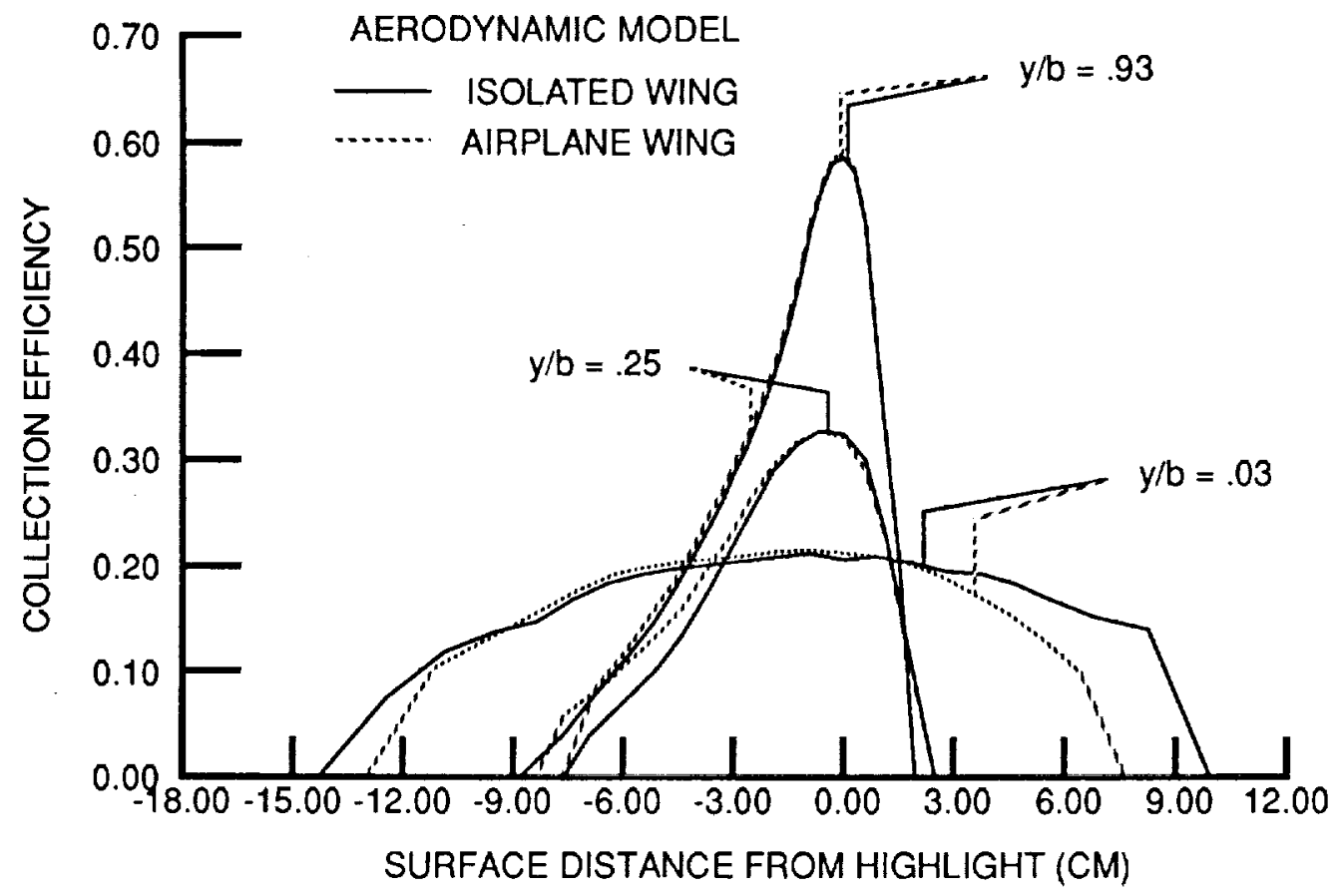

FIGURE 6. - COMPARISON OF COLLECTION EFFICIENCY FOR THE ISOLATED AND AIRPLANE WING AS A FUNCTION OF SURFACE DISTANCE AT SEVERAL SPANWISE LOCATIONS ON WING. FLIGHT CONDITIONS; AIRSPEED, $135 \mathrm{M} / \mathrm{S}$, AAOA; O DEGREES, DROP SIZE; $20 \mu \mathrm{m}$, STATIC TEMPERATURE; $9.3 \mathrm{C}$, STATIC PRESSURE; $89867 \mathrm{~Pa}$.

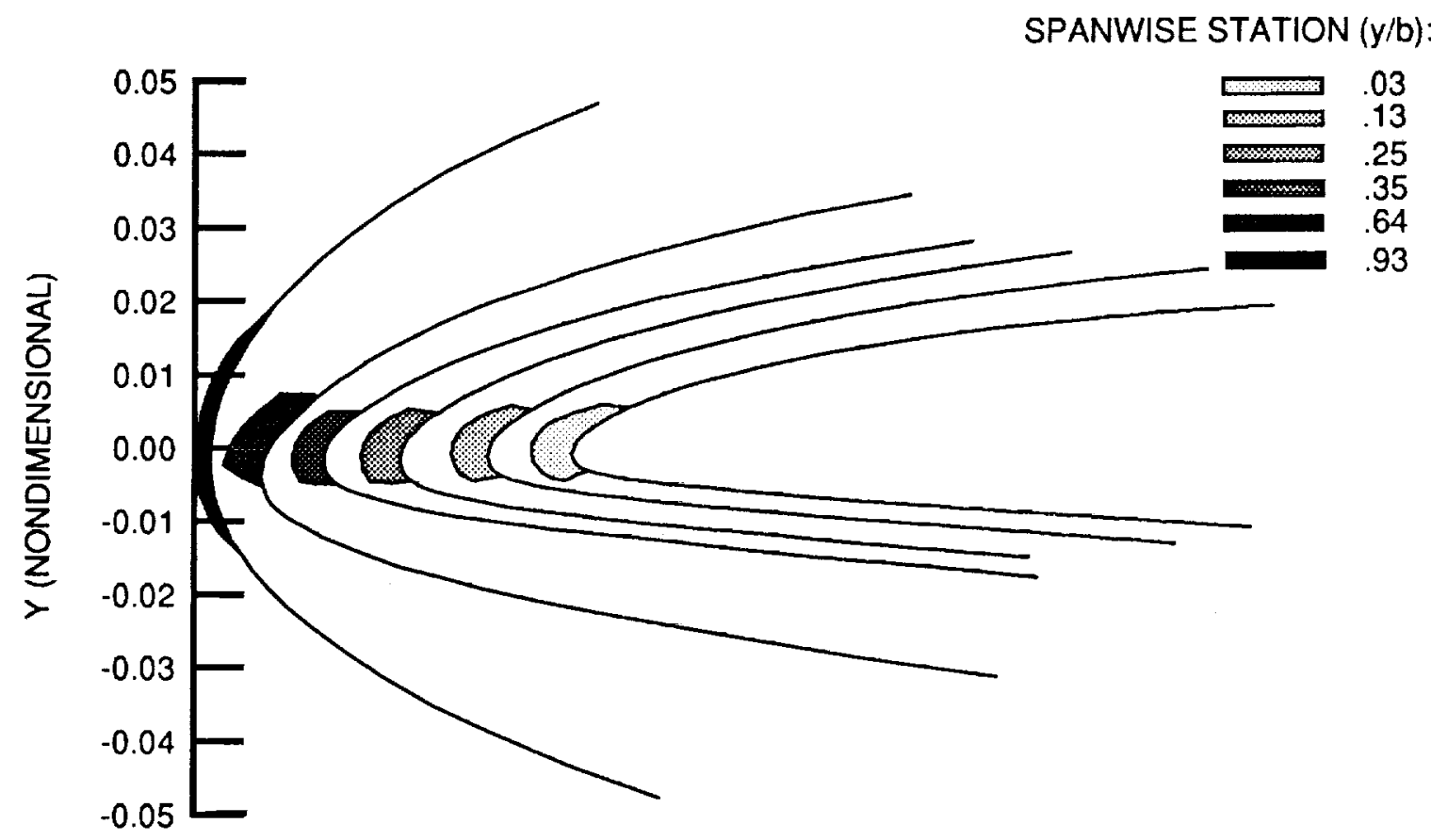

FIGURE 7. - CALCULATED ICE ACCRETIONS AT SEVERAL SPANWISE LOCATIONS ON AIRCRAFT WING. FLIGHT CONDITIONS; AIRSPEED, $135 \mathrm{M} / \mathrm{S}$, AAOA; 0 DEGREES, DROP SIZE; $20 \mu \mathrm{m}$, STATIC TEMPERATURE; -29.9 C. STATIC PRESSURE; $89867 \mathrm{~Pa}$, ICING TIME; 30 MINUTES. LWC; .2 G/M³ . 
SPANWISE STATION (y/b):

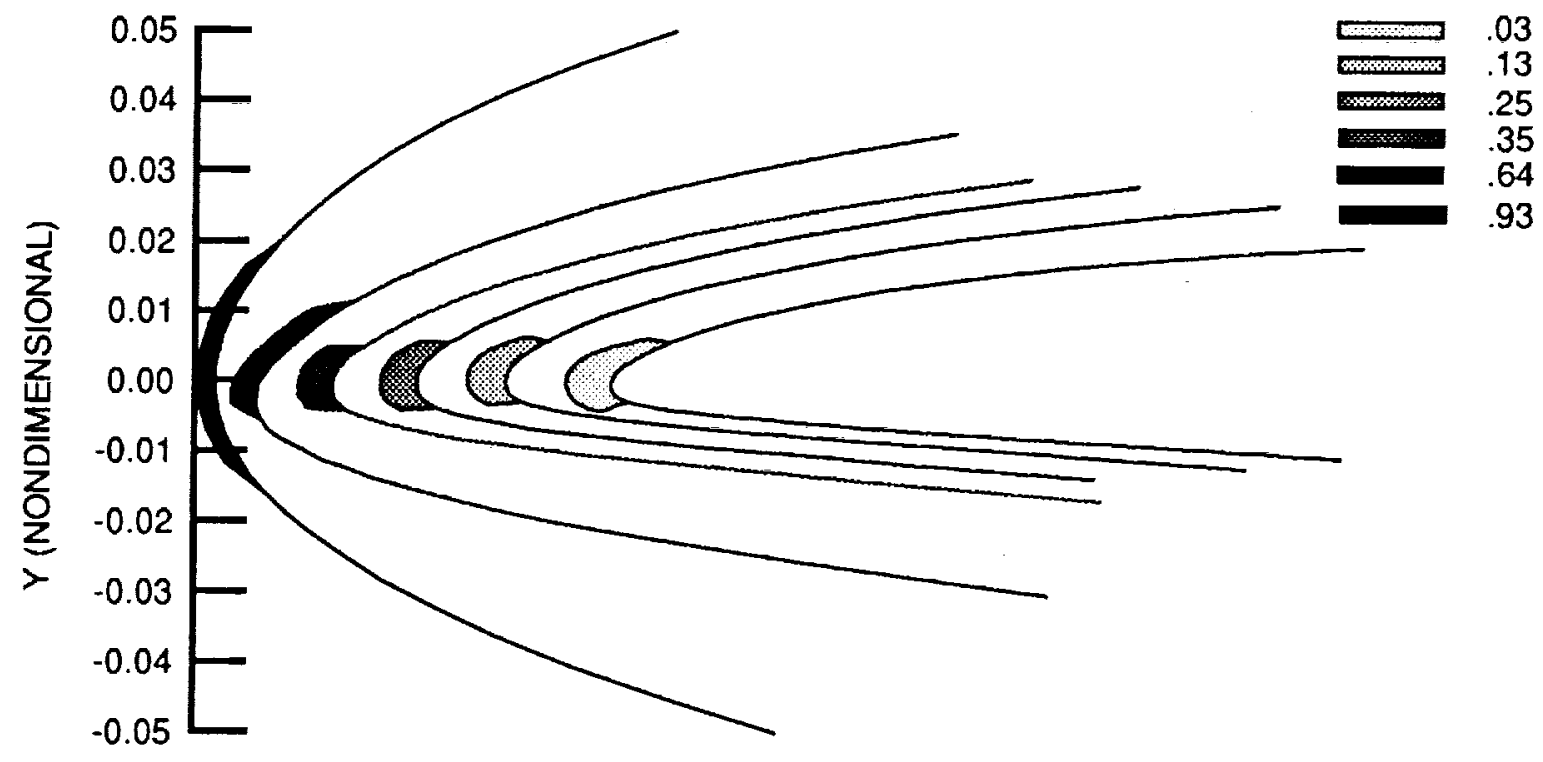

FIGURE 8. - CALCULATED ICE ACCRETIONS AT SEVERAL SPANWISE LOCATIONS ON ISOLATED WING. FLIGHT CONDITIONS; AIRSPEED, $135 \mathrm{M} / \mathrm{S}$, AAOA; O DEGREES, DROP SIZE; $20 \mu \mathrm{m}$, STATIC TEMPERATURE; -29.9 C, STATIC PRESSURE; 89867 Pa, ICING TIME; 30 MINUTES. LWC; $.2 \mathrm{G} / \mathrm{M}^{3}$.

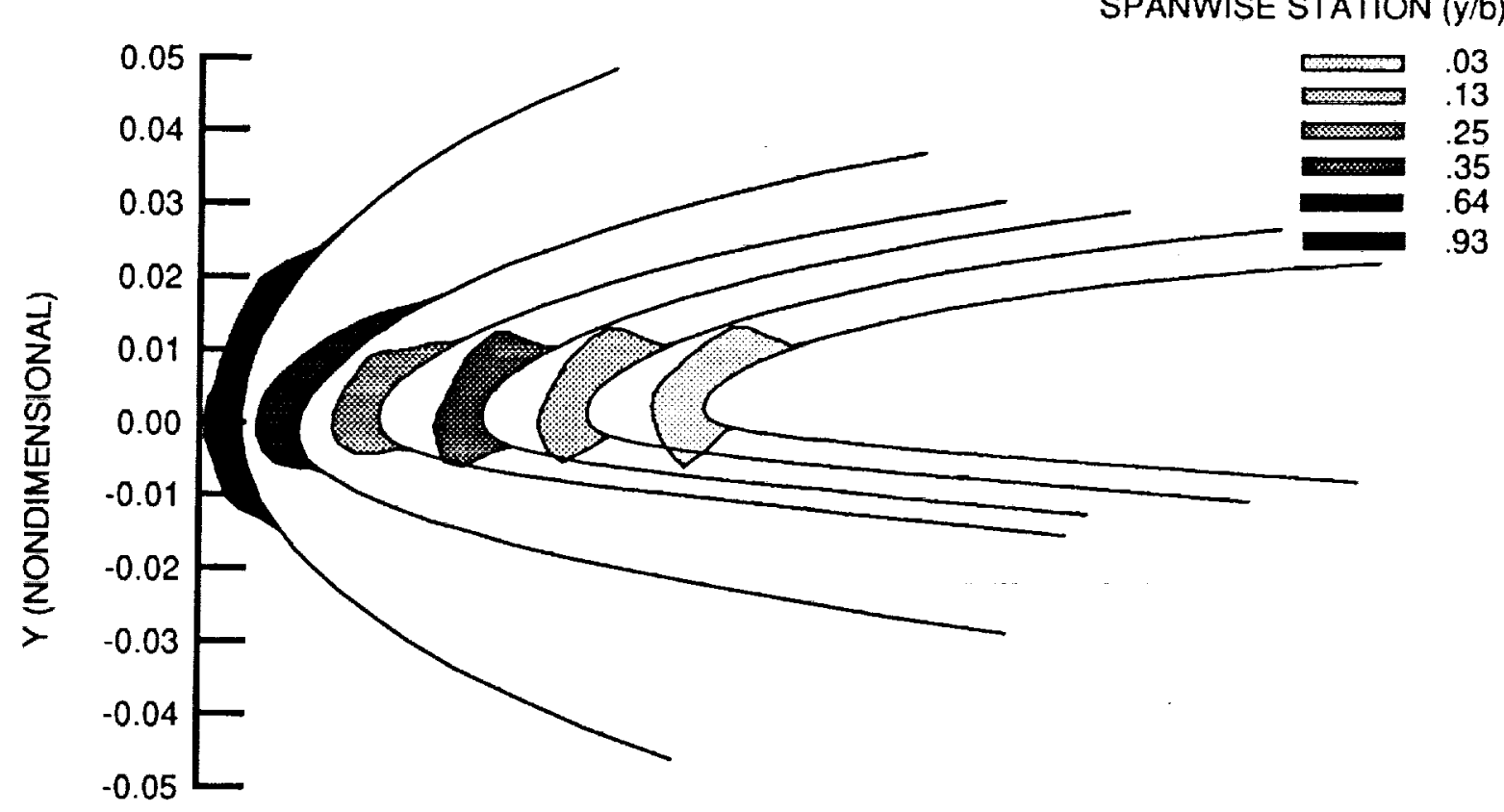

FIGURE 9. - CALCULATED ICE ACCRETIONS AT SEVERAL SPANWISE LOCATIONS ON AIRCRAFT WING. FLIGHT CONDITIONS; AIRSPEED, $135 \mathrm{M} / \mathrm{S}$, AAOA; 0 DEGREES, DROP SIZE; $20 \mu \mathrm{m}$, STATIC TEMPERATURE; -9.3 C, STATIC PRESSURE; $89867 \mathrm{~Pa}$, ICING TIME; 30 MINUTES. LWC; $.695 \mathrm{G} / \mathrm{M}^{3}$. 
SPANWISE STATION $(y / b)$ :

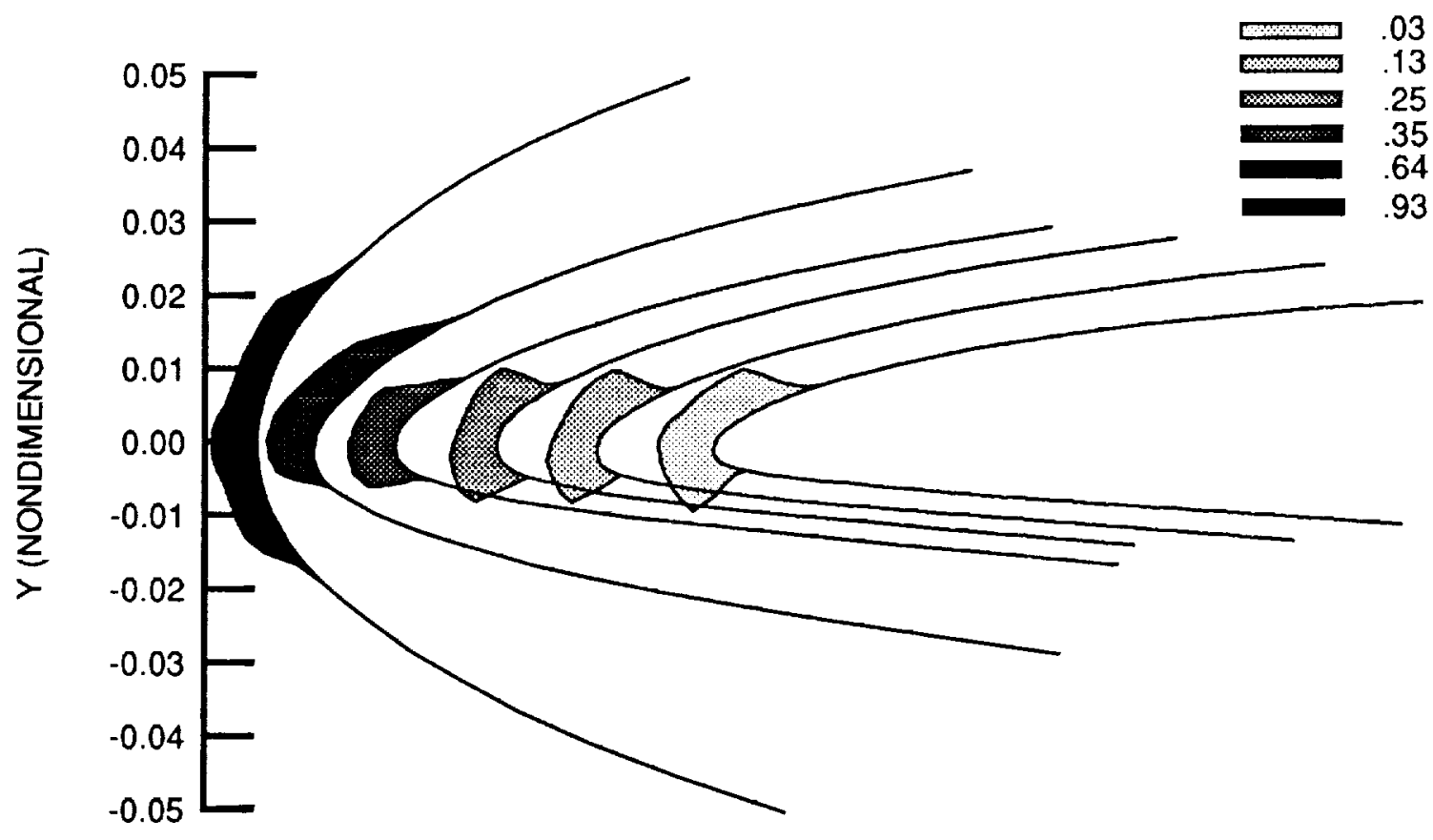

FIGURE 10. - CALCULATED ICE ACCRETIONS AT SEVERAL SPANWISE LOCATIONS ON ISOLATED WING. FLIGHT CONDITIONS; AIRSPEED, $135 \mathrm{M} / \mathrm{S}$, AAOA; 0 DEGREES, DROP SIZE; $20 \mu \mathrm{m}$, STATIC TEMPERATURE; -9.3 C, STATIC PRESSURE; $89867 \mathrm{~Pa}$, ICING TIME; 30 MINUTES. LWC; $.695 \mathrm{G} / \mathrm{M}^{3}$.

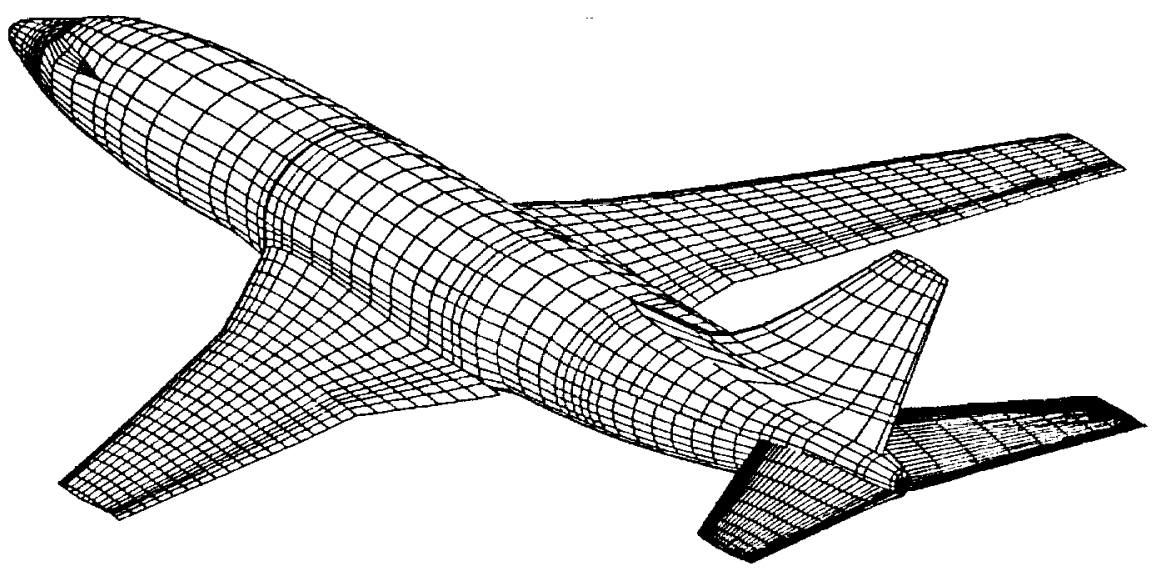

FIGURE 11. - PANEL REPRESENTATION OF AIRCRAFT USED IN HORIZONTAL TAIL CALCULATIONS. 


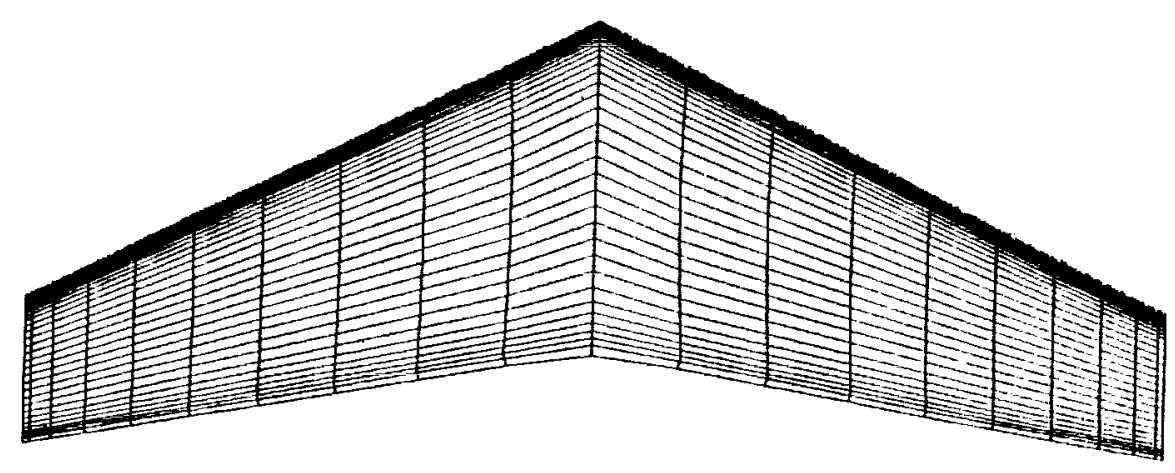

FIGURE 12. - TOP VIEW OF ISOLATED HORIZONTAL TAIL PANEL MODEL.

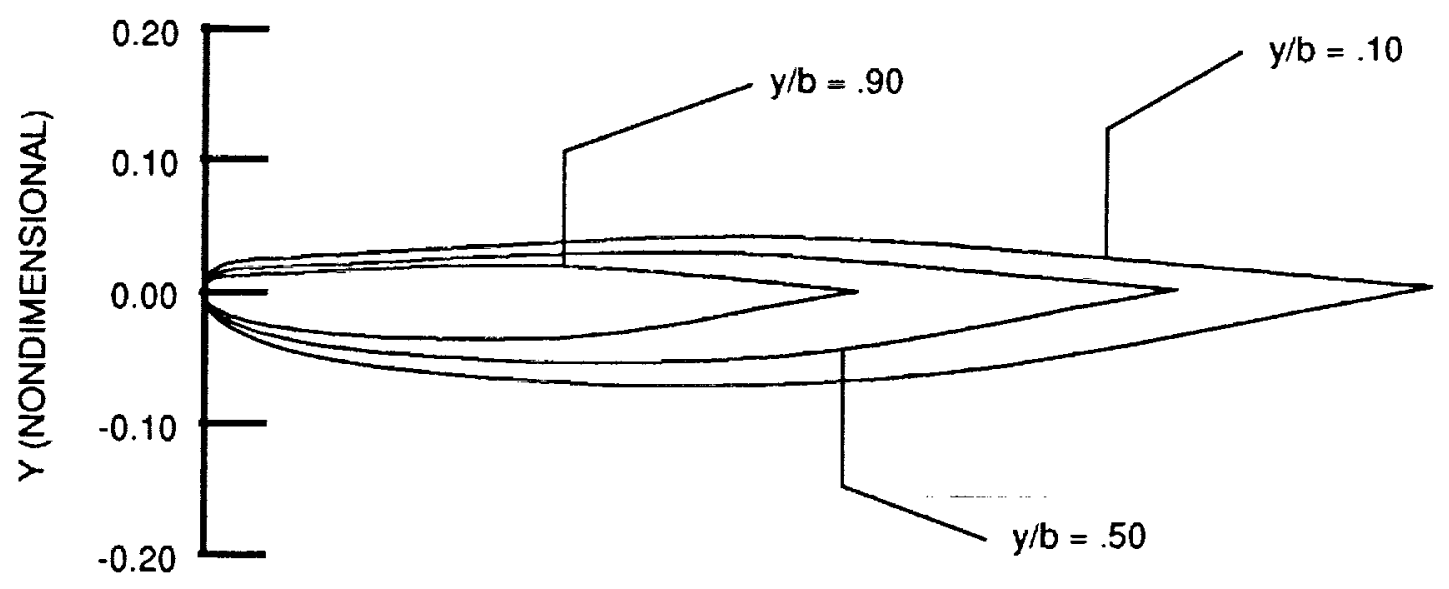

FIGURE 13. - HORIZONTAL TAIL PROFILES AT SEVERAL SPANWISE STATIONS. 


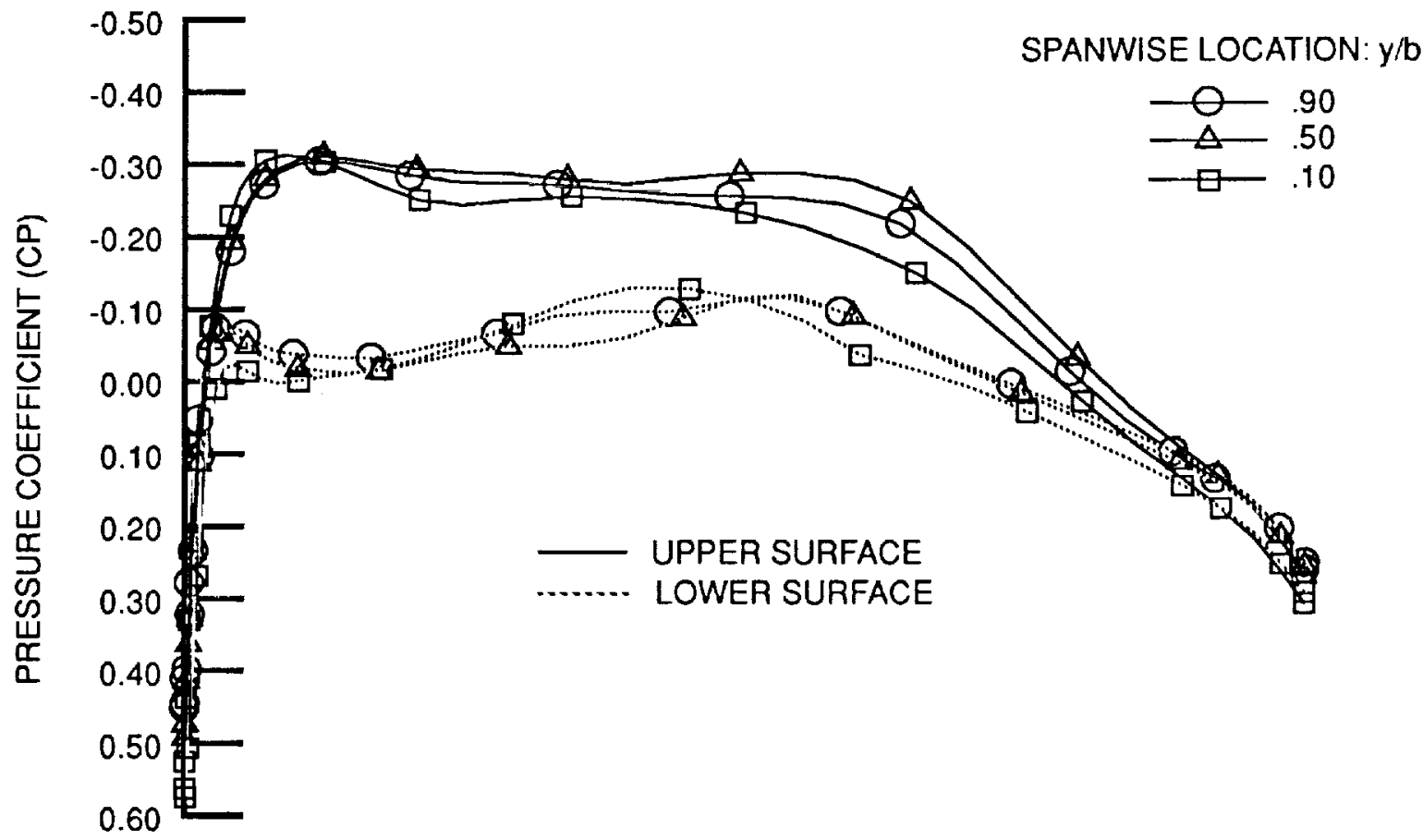

(a) AIRCRAFT HORIZONTAL TAIL.

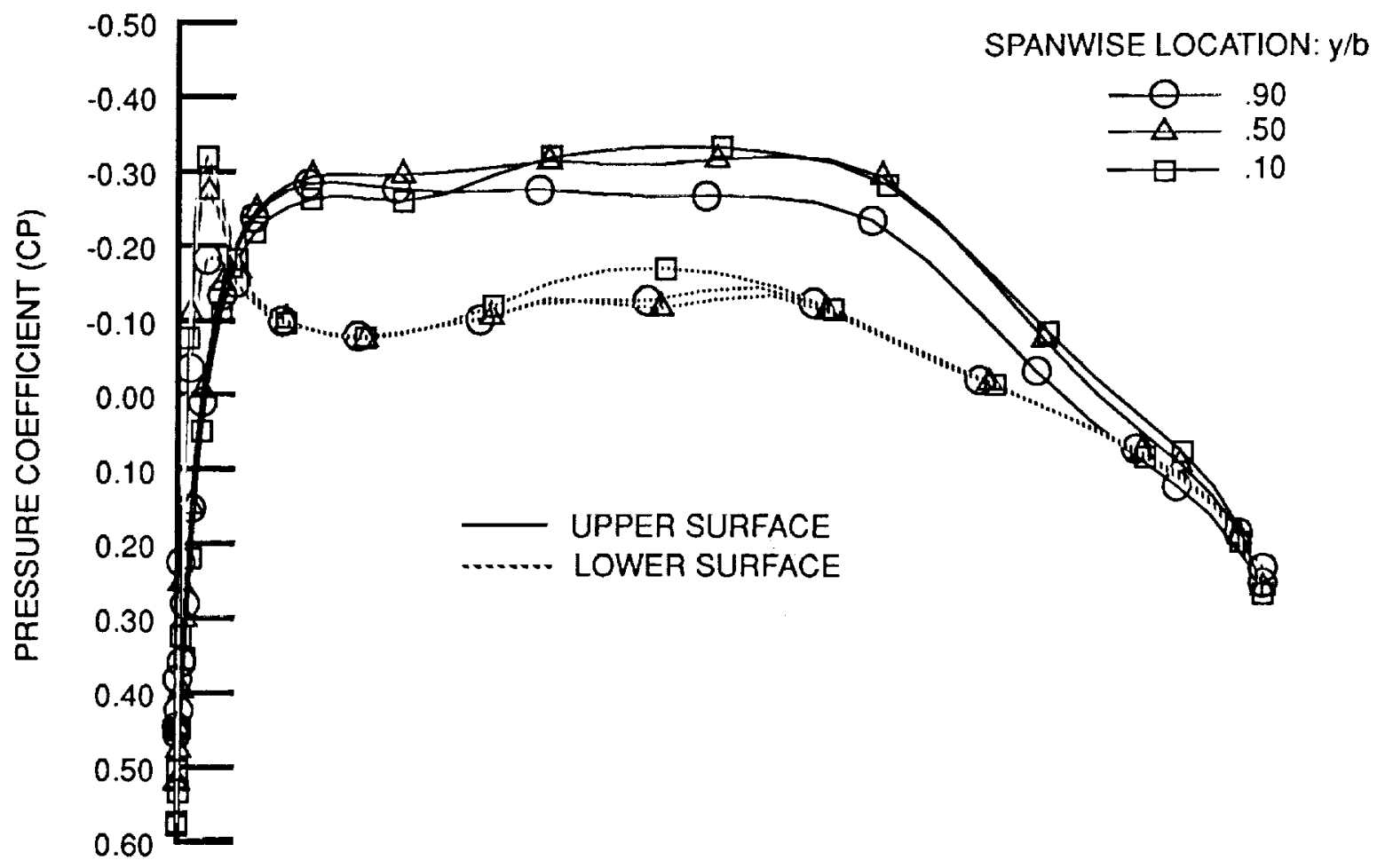

(b) ISOLATED HORIZONTAL TAIL.

FIGURE 14. - PRESSURE DISTRIBUTION AT SEVERAL SPANWISE LOCATIONS ON HORIZONTAL TAIL FOR AAOA OF O DEGREES. 


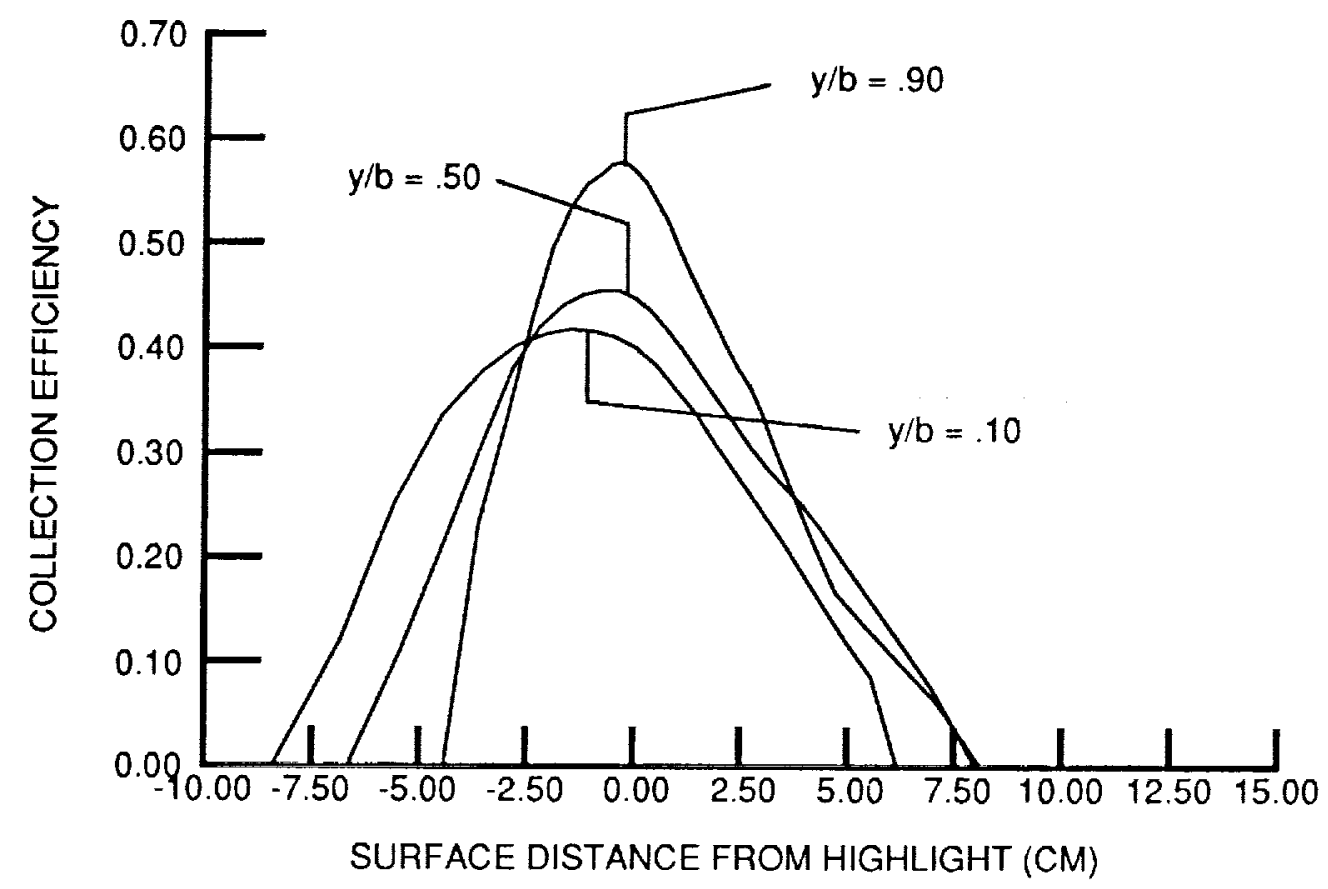

(a) AIRCRAFT HORIZONTAL TAIL.

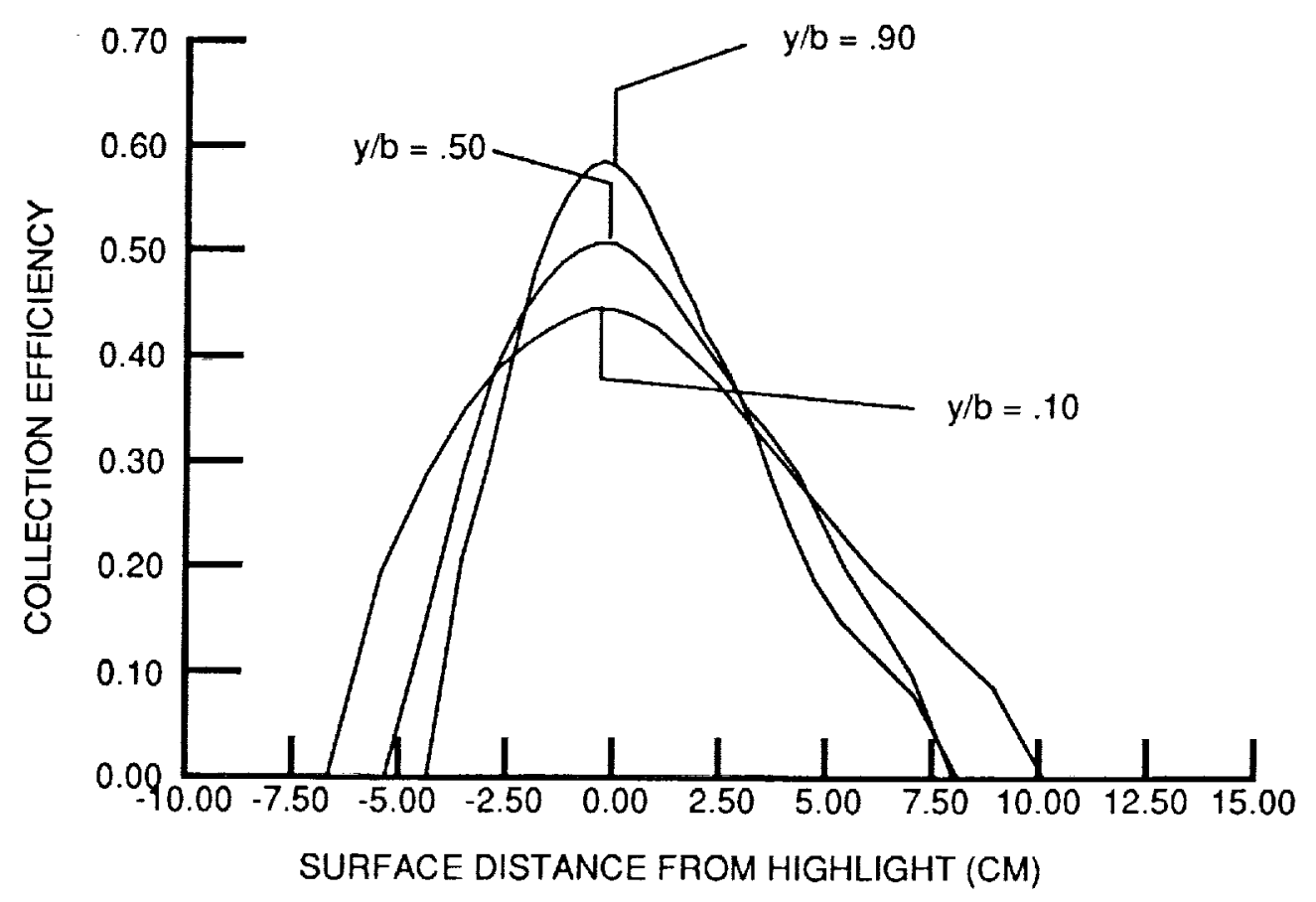

(b) ISOLATED HORIZONTAL TAIL.

FIGURE 15. - COLLECTION EFFICIENCY AS A FUNCTION OF SURFACE DISTANCE AT SEVERAL SPANWISE LOCATIONS ON HORIZONTAL TAIL. FLIGHT CONDITIONS; AIRSPEED, $135 \mathrm{M} / \mathrm{S}$, AAOA; 0 DEGREES, DROP SIZE; $20 \mu \mathrm{m}$, STATIC TEMPERATURE; -9.3 C, STATIC PRESSURE; $89867 \mathrm{~Pa}$. 


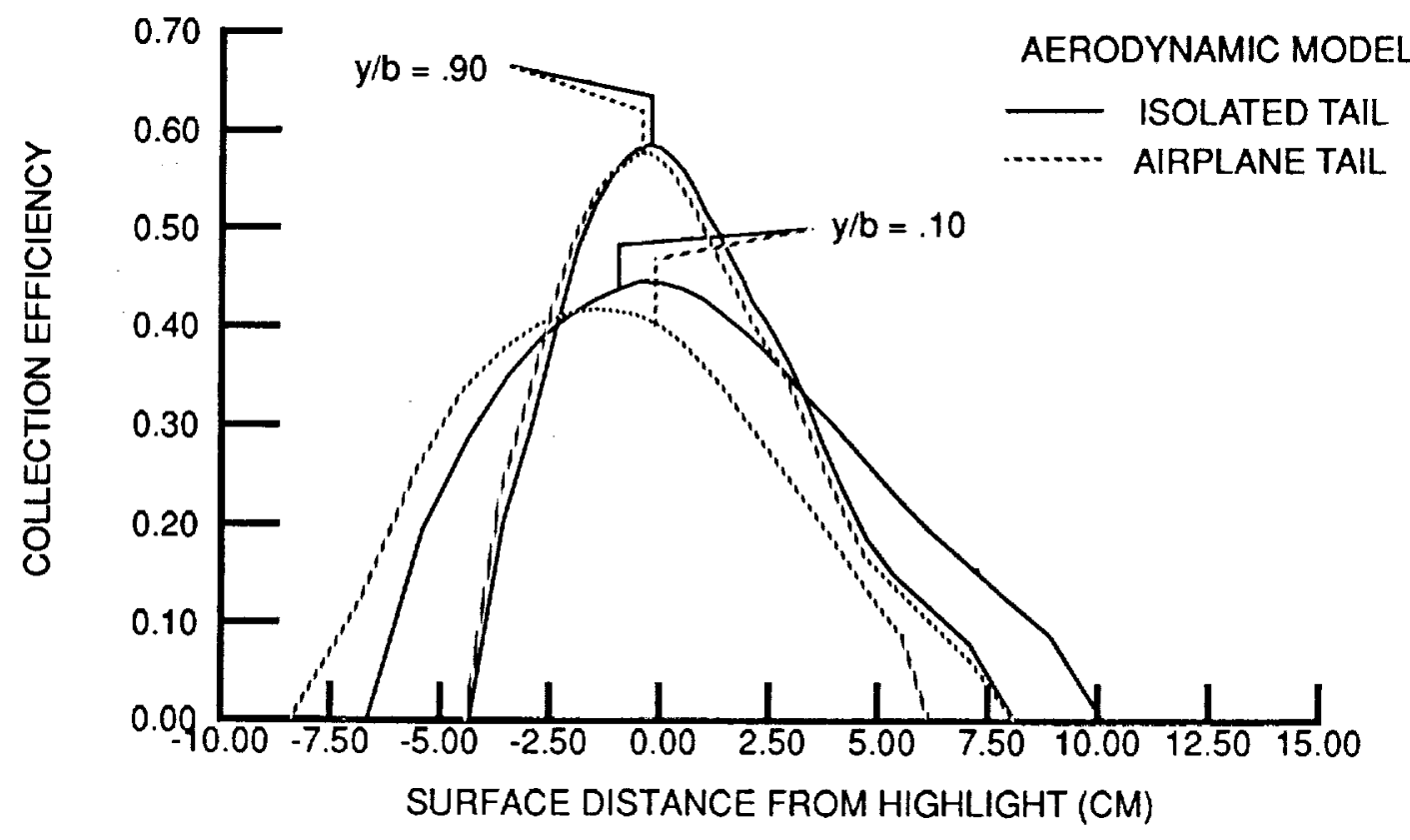

FIGURE 16. - COMPARISON OF COLLECTION EFFICIENCY FOR THE ISOLATED AND AIRPLANE HORIZONTAL TAIL AS A FUNCTION OF SURFACE DISTANCE AT SEVERAL SPANWISE LOCATIONS ON WING. FLIGHT CONDITIONS; AIRSPEED, $135 \mathrm{M} / \mathrm{S}$, AAOA; 0 DEGREES, DROP SIZE; 20 $\mu \mathrm{m}$, STATIC TEMPERATURE; -9.3 C, STATIC PRESSURE; $89867 \mathrm{~Pa}$.

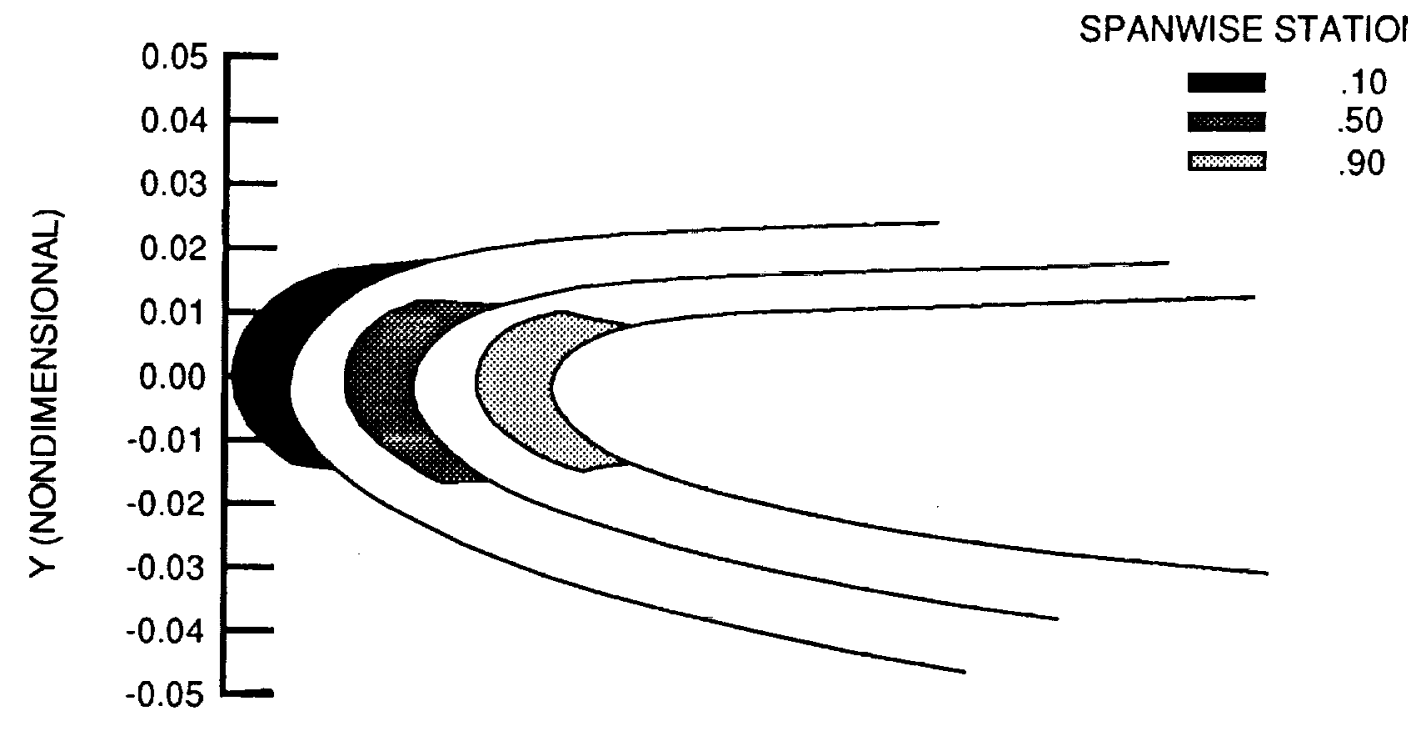

FIGURE 17. - CALCULATED ICE ACCRETIONS AT SEVERAL SPANWISE LOCATIONS ON AIRCRAFT HORIZONTAL TAIL. FLIGHT CONDITIONS; AIRSPEED, $135 \mathrm{M} / \mathrm{S}$, AAOA; O DEGREES, DROP SIZE; $20 \mu \mathrm{m}$, STATIC TEMPERATURE; -29.9 C, STATIC PRESSURE; $89867 \mathrm{~Pa}$, ICING TIME; 30 MINUTES. LWC; .2 G/M ${ }^{3}$. 


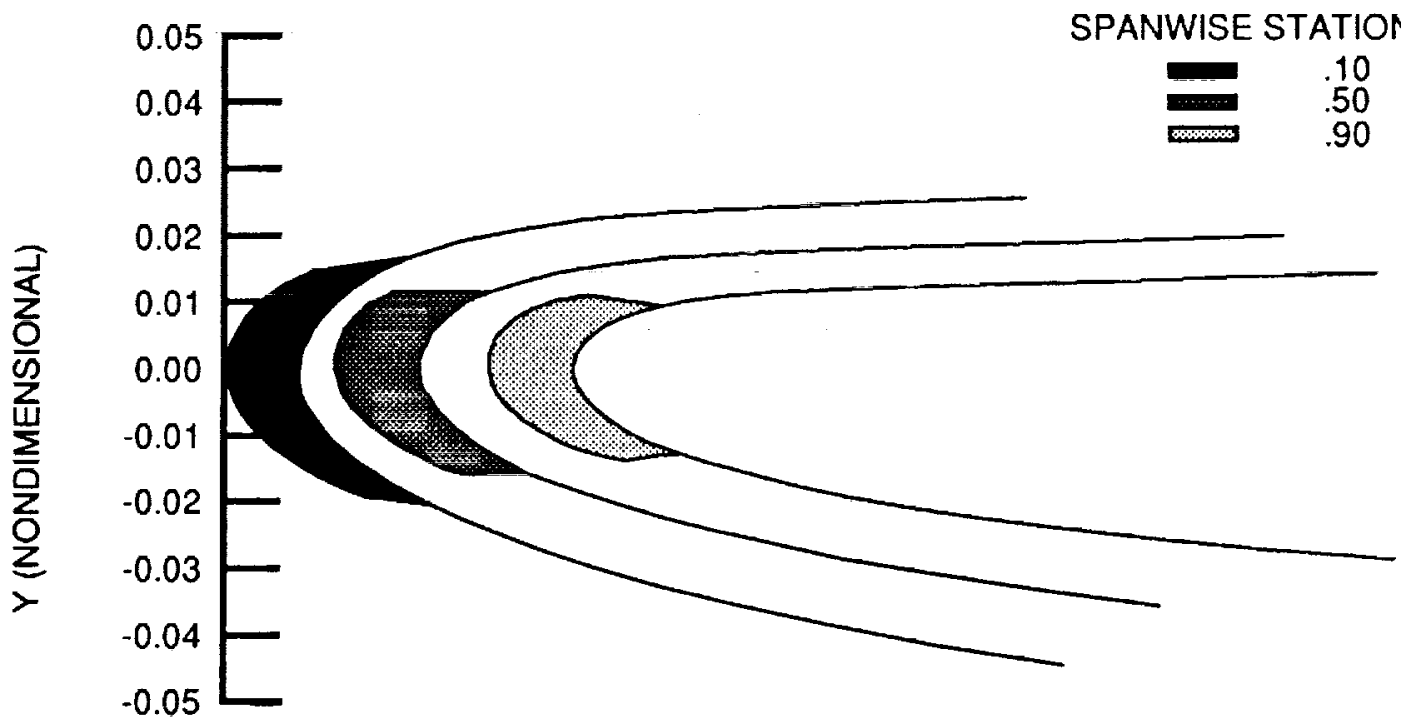

FIGURE 18. - CALCULATED ICE ACCRETIONS AT SEVERAL SPANWISE LOCATIONS ON ISOLATED HORIZONTAL TAIL. FLIGHT CONDITIONS; AIRSPEED, $135 \mathrm{M} / \mathrm{S}$, AAOA; 0 DEGREES, DROP SIZE; $20 \mu \mathrm{m}$, STATIC TEMPERATURE; -29.9 C, STATIC PRESSURE; $89867 \mathrm{~Pa}$, ICING TIME; 30 MINUTES. LWC; $2 \mathrm{G} / \mathrm{M}^{3}$.

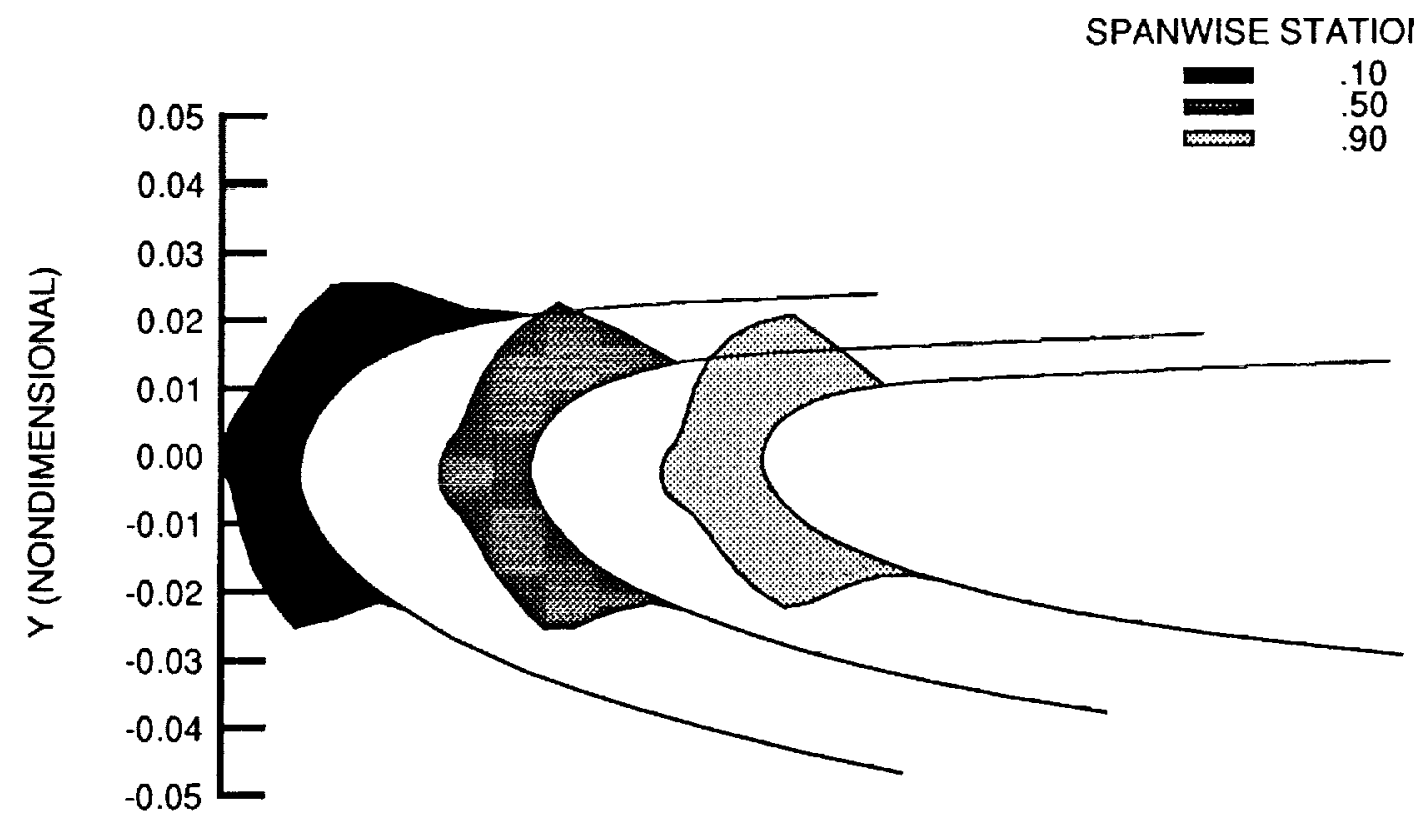

FIGURE 19. - CALCULATED ICE ACCRETIONS AT SEVERAL SPANWISE LOCATIONS ON AIRCRAFT HORIZONTAL TAIL. FLIGHT CONDITIONS; AIRSPEED, $135 \mathrm{M} / \mathrm{S}$, AAOA; O DEGREES, DROP SIZE; $20 \mu \mathrm{m}$, STATIC TEMPERATURE; -9.3 C, STATIC PRESSURE; $89867 \mathrm{~Pa}$, ICING TIME; 30 MINUTES. LWC; .695 G/M ${ }^{3}$. 

Public reporting burden for this collection of information is estimated to average $f$ hour per response, including the time for reviewing instructions, searching existing data sources, gathering and maintaining the data needed, and completing and reviewing the collection of information. Send comments regarding this burden estimate or any other aspect of this collection of information, including suggestions for reducing this burden, to Washington Headquarters Services, Direclorale for information Operations and Reports. 1215 Jefferson Davis Highway, Suite 1204, Arlington, VA 22202-4302, and to the Office of Management and Budget, Paperwork Feduction Project (0704-0188), Washington, DC 20503.

\begin{tabular}{|l|c|c|}
\hline 1. AGENCY USE ONLY (Leave blank) & $\begin{array}{c}\text { 2. REPORT DATE } \\
\text { January } 1993\end{array}$ & $\begin{array}{r}\text { 3. REPORT TYPE AND DATES COVERED } \\
\text { Technical Memorandum }\end{array}$
\end{tabular}

\section{TITLE AND SUBTITLE}

5. FUNDING NUMBERS

Ice Accretion Prediction for a Typical Commercial Transport Aircraft

6. AUTHOR(S)

C.S. Bidwell

7. PERFORMING ORgANIZATION NAME(S) AND ADDRESS(ES)

8. PERForming ORganization REPORT NUMBER

National Acronautics and Space Administration

Lewis Research Center

Cleveland, Ohio 44135-3191

E-7499

9. SPONSORING/MONITORING AGENCY NAMES(S) AND ADDRESS(ES)

10. SPONSORING/MONITORING AGENCY REPORT NUMBER

National Aeronautics and Space Administration

Washington, D.C. 20546-0001

NASA TM-. 105976

AIAA-93-0174

\section{SUPPLEMENTARY NOTES}

Prepared for the 3 ist Acrospace Sciences Mecting and Exhibit sponsored by the American Institute of Acronatics and Astronauties, Reno, Nevada, January 11-14, 1993. Responsible person, C.S. Bidwell, (216) 433 3947.

12a. DISTRIBUTION/AVAILABILITY STATEMENT

12b. DISTAIBUTION CODE

Unclassified - Unlimiled

Subject Catcgories 02 and 03

\section{ABSTRACT (Maximum 200 words)}

Ice accretion calculations were made for a modern commercial transport using the NASA, Lcwis L.FWICE3D ice accretion code. The ice accretion calculations were made for the wing and horizontal tail using both isolated flow models and flow models incorporating the entire airplanc. The isolated flow model calculations were made to assess the validity of using these simplified models in lieu of the entire model in the ice accretion analysis of full aircralt. Ice shapes typifying a rime and a mixed ice shape were generated for a 30 minute hold condition. In general, the calculated ice shapes looked reasonable and appeared representative of a rime and a mixed ice conditions. The isolated flow model simplification was good for the main wing exeept at the root where it overpredicted the amount of accreted ice relative to the full aircraft flow model. For the horizontal tail the size and amount of predicted ice compared well for the two flow models, but the position of the accretions were more towards the upper surface for the aircraft flow model relative to the isolated flow model. This was attributed to downwash from the main wing which resulted in a lower effective angle-of-attack for the aircraft horizontal tail relative to the isolated horizontal tail.

\begin{tabular}{|c|c|c|}
\hline $\begin{array}{l}\text { 14. SUBJECT TERMS } \\
\text { Aircraft icing }\end{array}$ & & \\
\hline $\begin{array}{l}\text { 17. SECURITY CLASSIFICATION } \\
\text { OF REPORT } \\
\text { Unclassified }\end{array}$ & $\begin{array}{l}\text { 18. SECUAITY CLASSIFICATION } \\
\text { OF THIS PAGE } \\
\text { Unclassified }\end{array}$ & $\begin{array}{l}\text { 19. SECURITY CLASSIFICATION } \\
\text { OF ABSTRACT } \\
\text { Unclassified }\end{array}$ \\
\hline
\end{tabular}

